\title{
THE MALVEIRA FIRE TEST: FULL-SCALE DEMONSTRATION OF FIRE MODES IN OPEN- PLAN COMPARTMENTS
}

4

Juan P. Hidalgo ${ }^{1,2^{*}}$, Tristan Goode ${ }^{1}$, Vinny Gupta ${ }^{1}$, Adam Cowlard ${ }^{3}$, Cecilia AbecassisEmpis ${ }^{3}$, Jamie Maclean², Alastair I. Bartlett ${ }^{2}$, Cristián Maluk ${ }^{1,2}$, José M. Montalváa , Andrés F. Osorio $^{1}$, and José L. Torero ${ }^{5}$

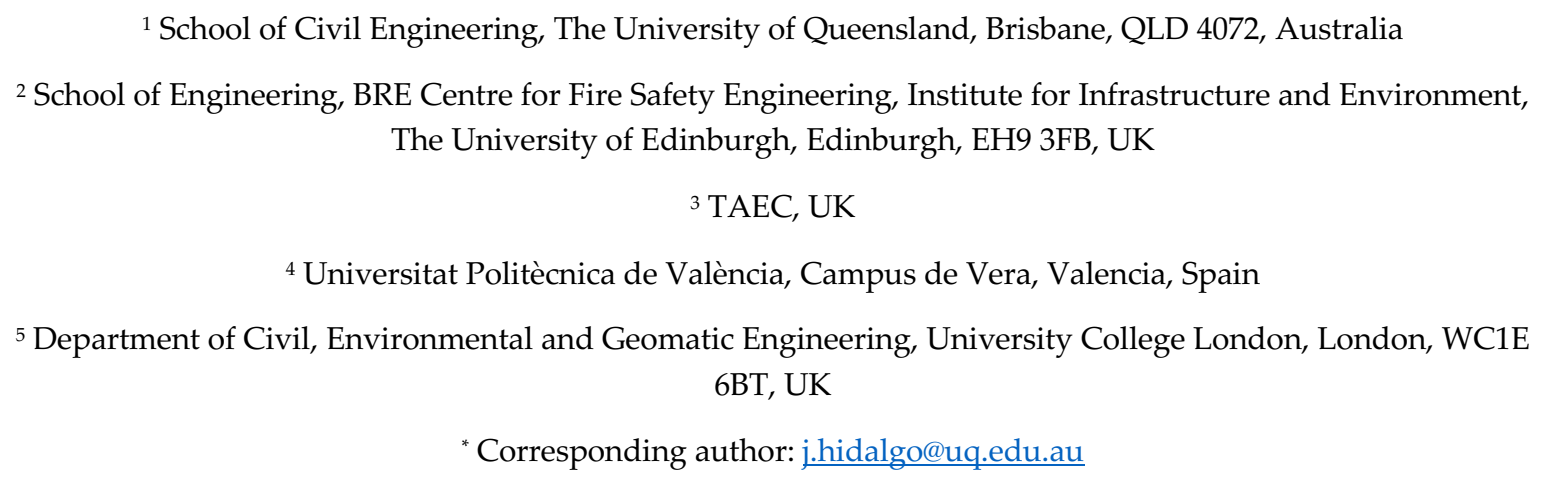

\section{Abstract}

This paper aims to characterize dynamics of a fire in the Large-Scale Demonstrator Malveira Fire Test, a full-scale fire experiment carried out in a disused industrial building in Portugal. The Malveira Fire Test is the second stage in the series of full-scale experimental programmes developed for the Real Fires for the Safe Design of Tall Buildings project at the University of Edinburgh. This experiment is intended to act as a real-building demonstration of fire dynamics in large open-floor plan compartments and has as objective to provide a data set to contrast methodologies aiming at design fire inputs representative of real fire dynamics in compartments typical of tall buildings.

The Malveira Fire Test showed three distinct fire behaviour modes characterised by the ratio between the velocities of the fire front $\left(V_{S}\right)$ and the burnout front $\left(V_{B O}\right)$; a travelling fire mode with $V_{S} / V_{B O} \approx 1$, a growing fire mode with $V_{S} / V_{B O}>1$ and a fully-developed fire mode with $V_{S} / V_{B O} \rightarrow \infty$. The three modes are found to have a correlation with the incident heat flux onto the surface of fuel caused by the resulting energy distribution within the compartment. The energy distribution appears to be a function of the characteristics of the compartment, the fuel distribution and the resulting aerodynamics. A description of the instrumentation and analysis of results are presented to support a theoretical justification for the transitions between fire modes.

\section{Keywords}

Enclosure fire dynamics, large-scale experiments, compartment fire framework, tall buildings 


\section{$1 \quad 1$ Introduction}

2 The built environment has seen rapid growth in recent decades as new structures continue to 3 evolve in height, construction materials, compartmental composition and use [1]. This growth

4 shows no sign of slowing as the rate of complex and tall buildings being constructed continues 5 to rise worldwide, with a $402 \%$ increase in the number of buildings exceeding $200 \mathrm{~m}$ in height 6 in 2017 alone [1, 2]. The forces driving this progression are a combination of financial, political7 environmental, and technological factors, which have resulted in significant advancements in 8 construction techniques, cost optimisation, innovative materials, ease of construction, and 9 architectural innovation [1]. One of the key trends of mainstream architecture since as far back 10 as the 1920s is the desire for open, flexible volumes saturated by natural light through multiple 11 large openings [3]. The result of this trend is modern tall buildings of all occupancies having 12 large open plan compartments.

13 The principles and terminology commonly used to define compartment fire dynamics have 14 been defined through the study of small compartments where the temporal evolution of the 15 fire dominated over its spatial evolution [3]. Extrapolation of these concepts and terminology 16 have found significant limitations when addressing the dynamics of a fire in large open plan 17 compartments.

18 Current understanding is derived from pioneering research predominantly developed 19 between the 1950s and 1990s, brought by the need for more explicit descriptions of the fire environment and engineering methods to assess the performance of fire-resistant partitions and structures. From these works, the Compartment Fire Framework was developed, which defined the fire dynamics as a function of restrictions imposed by compartmentation, with limited openings, typical of relatively small compartments [3-4].

At present, the provision of fire-safe designs within tall buildings currently hinges on three essential components [1]:

1. Ensuring effective vertical compartmentation that confines the fire to one floor,

2. Providing structural integrity that extends beyond the burnout of the fuel load, and

3. Maintaining clear egress routes for all occupants.

These three design components strongly rely on the characterisation of the fire dynamics beyond the early growth stage of the fire as the primary input parameter [1]. The Compartment Fire Framework still underpins the engineering tools used to quantify all these aspects. In cases where this framework does not apply, the thermal boundary condition imposed on loadbearing structural systems from the fire is far from being completely resolved [4]. The applicability and limitations to the use of the Compartment Fire Framework in these circumstances remains unclear. Therefore, detailed study of fires in large open plan compartments is required so that fire safety engineering principles can adapt to these new rapid developments in construction. This study attempts to provide, by means of a large well instrumented test, further clarity on the behaviour of a fire in a large open plan compartment. 
2 The origins of fire compartment studies stem from the work of Ingberg in 1928 [5], driven by

3 the high death rate associated with building fires and recognition that they tended to burn

4 until structural collapse [6]. Large-scale fire experiments at the National Bureau of Standards

5 (NBS) quantified the duration and intensity of building fires [6], whereas Ingberg's work

6 related these parameters to an equivalent exposure to the standard furnace time-temperature

7 curve during a fire-resistance test. Ingberg initiated the pioneering period of fire safety

8 engineering research, which formed the basis for the Compartment Fire Framework. The main

9 objective of these key studies was to characterise the behaviour of fully-developed fires within

10 compartments in order to define the thermal loads for structural assessment. Fujita and

11 Kawagoe's early work [7-9] realised the limitations of the standard fire resistance test and

12 established that the compartment fire characteristics and their surroundings (i.e. geometry,

13 fuel, ventilation etc.) are intrinsically linked, resulting in a very complex interaction in the

14 event of a fire [10].

15 Due to the complexity of the coupling between compartment fire dynamics and the

16 compartment itself, the need for simplifications was recognised in order to quantify behaviour

17 for design purposes. This was achieved by Thomas and Heselden [11], who demonstrated

18 that, for a specific range, the compartment and opening geometries govern the physical

19 behaviour of the fire as the fire is controlled by the inflow of air into the compartment. Beyond

20 this specified range, the openings are considered sufficiently large enough to no longer be a

21 governing factor. Thus the amount of fuel surface available governs the fire. The former was

22 labelled Regime I (ventilation-controlled) fires and the latter Regime II (fuel-controlled) fires.

23 The traditional understanding of these fire regimes was expanded on by Harmathy [12], and

24 further revised more recently by Majdalani [3]. Majdalani [3] discusses the importance of the compartment geometry on the aerodynamics of the air flow and on the conditions that lead to the transition between both regimes. Within the Compartment Fire Framework this is related to flashover and has been extensively studied [10], but as the geometry of the compartment strongly departs from a small cube, this transition has the potential to be more complex. The nature of Majdalani's experiments [3] did not allow for a more detailed exploration of this transition.

A Regime I fire, a fully-developed post-flashover fire, fills the compartment with smoke due to the limited ventilation, causing rich combustion and high soot concentration. Flow within the compartment is dominated by the expansion of hot gases, allowing to neglect mass and momentum transfer. A key characteristic of Regime I fires is that the compartment exhibits high, uniform temperatures and openings must allow for the transfer of mass that is driven by the hydrostatic pressure difference between the inside and outside of the compartment [4].

A Regime II fire is also fully-developed, however, it is dictated by the fuel surface area available for combustion. Large openings allow for air exchange with the outside, allowing for high momentum buoyant flows that hinder the correlation between ventilation and fuel burning rate [3]. The significant momentum prevents the retention of smoke and results in the lack of a well-defined smoke layer. Internal temperatures are therefore generally lower. 
1 The Compartment Fire Framework in its current form focuses on Regime I fires. Researchers, 2 through increased simplifications, were able to articulate it theoretically and the data obtained 3 from testing showed more clear trends in comparison to the large scatter that was associated 4 with results from Regime II fire experiments. Furthermore, due to the higher temperatures 5 observed in the Regime I, this was deemed the most 'severe' scenario for the structure. 6 Advancements in research have typically exclusively focused on characterising the energy 7 exchange and burning rates within a compartment as functions of the opening geometry [4]. 8 Tools were then developed, allowing for rapid application of 'conservative' bounding thermal 9 loads to structural design, which have been integrated into design standards and building 10 practices globally [13]. Regime II fires, being more complex, have not been researched and 11 developed theoretically. In a similar manner, the conditions leading to the transition between 12 Regime I and Regime II have also not been studied in detail.

13 The Regime I design methods assume a worst-case uniform temperature, which is much higher 14 than the apparent range of possible temperatures of Regime II fires. The lack of correlation 15 between the actual fire behaviour in open plan compartments and current fires used for 16 design may lead to inadequately designed structures [14]. Architectural evolution has led to tall, open-plan structures with interconnected compartments being the norm. Nevertheless, as the fire design strictly depends on compartmentation, a clear disparity between contemporary infrastructure and definitions of compartment fire dynamics has arisen. While fire characteristics of Regime II fires have historically been deemed less severe, in contemporary open-plan infrastructure, smoke and therefore heat can be transferred away from the fire yet still remain within the building. It will consequently continue its exchange of energy with the structure and unburnt combustible materials, even in areas that are remote from the fire. This introduces a possibility of spatially variant energy distributions within large compartments, which modern structural fire engineering has shown that can introduce complex thermally induced forces within a structural system, even at lower temperatures [15]. Such loading conditions are not considered by traditional approaches to establishing structural performance under thermal loading. [16].

30 The more widespread distribution of generated heat can lead to fires in large compartments 31 exhibiting behaviour referred to as "travelling fires", where fuel is burned over a limited area. This limited area will spread across the floor plate [17]. Travelling fire theory assumes two regions in the compartment - the near field and the far field. The near field refers to the region where the fire itself is located, while the far field is the areas remote from the fire. These two regions are assumed to remain constant in size but 'travel' through the compartment as the flame spreads and fuel is consumed [18].

Calculation methods to approach "travelling fire" behaviour have been developed in the last decade [17-21]. In the case of reference [17] a temperature distribution was extracted from a Computational Fluid Dynamics (CFD) calculation and used to calculate the spatial and 40 temporal evolution of the heat flux to the structure. Later studies [18-21] substitute the CFD 41 calculations by different correlations and simplified approaches towards defining spatial 42 temperature histories. The simplified approaches are based on the assumption that the fire 
characteristics will not change as the fire spreads through the compartment. Furthermore, the

2 correlations used are based on fires that have not attained flashover. While this approach

3 allows for a more practical application of the "Travelling Fires" concept, it is clear that it relies

4 on many assumptions and simplifications that have still not been fully validated with

5 adequate experimental data.

\section{$6 \quad 1.2$ Real Fires for the Safe Design of Tall Buildings}

7 In recent years, the University of Edinburgh undertook the Real Fires for the Safe Design of Tall

8 Buildings (RFSDTB) project, which aimed at producing a methodology that could be used to

9 provide design fire inputs representative of real fire dynamics in large open-plan

10 compartments typical of tall buildings. The RFSDTB project consisted of two series of fullscale experimental programmes, the Edinburgh Tall Building Tests and the Large-Scale Demonstrator Malveira Fire Test.

In 2013, the Edinburgh Tall Building Tests (ETFT) programme was carried out at the Building Research Establishment, Watford, United Kingdom [22]. The first stage of tests (Jan-May 2013) consisted of gas burner tests in a compartment of internal dimensions $5 \mathrm{~m}$ (width) $\times 18 \mathrm{~m}$ (length) $\times 2 \mathrm{~m}$ (height), and where different fire and ventilation modes were replicated. The second stage (May-June 2013) consisted of two wood crib tests in the same compartment with two different static ventilation conditions. The gas burner tests provide characteristic energy distributions for different fire and ventilation modes with precribed energy input (heat release rate). Three different fire modes were studied based on the relationship between the spread velocity of the fire front $\left(V_{S}\right)$ and the spread velocity of the burnout front $\left(V_{B O}\right)$ :

1. Mode 1: a fully-developed fire where $V_{S} / V_{B O} \rightarrow \infty$ (representative of a post-flashover).

2. Mode 2: a growing fire where $\frac{V_{S}}{V_{B O}}>1$.

3. Mode 3: a "travelling fire" where $V_{S} / V_{B O} \approx 1$.

Three ventilation modes where studied based on the inverse opening factor $\left(\phi^{\prime}=\frac{A_{T}}{A_{W} \sqrt{H}}\right)$ :

1. Static ventilation with $\phi^{\prime}=4.1$.

2. Static ventilation with $\phi^{\prime}=23.3$

3. Variable with the inverse opening factor transistioning from $\phi^{\prime}=23.3$ to $\phi^{\prime}=4.1$ (indicating increasing opening area as would be the case with window breakage).

Preliminary results from energy distribution analyses applied for the gas burner stage have been presented by Maluk et al. [23]. These clearly indicate different characteristic energy distributions within the compartment for the aforementioned fire modes and ventilation conditions. The wood crib fires were described briefly by Torero et al [4]. These test highlighted that a transition between the three modes used for ETFT gas burner tests was possible and, for the specific fuel configuration used, seemed to be a strong function of the ventilation conditions.

In 2014, a single full-scale fire experiment was carried out in a disused industrial building in 
1 stage, and try to observe some or all of these fire modes. This paper describes the experimental 2 compartment in the LSD Malveira Fire Test, including installed sensors array, main results and 3 an initial analysis of the experimental output data. Data will be made available through the

4 University of Edinburgh Data Share repository
5 (https://datashare.is.ed.ac.uk/handle/10283/3109) along with data from the Edinburgh Tall 6 Buildings Fire Tests.

\section{Description of the compartment}

8 The compartment selected for the experiment was originally an open-plan office within a two9 storey building. At the time of the experiment, the building was used by the Fire Service of 10 Malveira (Bombeiros Voluntários da Malveira) to practise firefighting techniques and observe 11 fire growth phenomena. The office compartment was selected for this experiment due to its 12 similarity in dimensions and opening characteristics to previous purpose-built experiments 13 from this project [22]. Even though this industrial building does not correspond to a tall 14 building, which is the main scope for this research, the key feature of this compartment is the open plan space geometry, representative of office spaces in tall buildings [22]. The building was constructed as a concrete frame structure with masonry block infill. The layout and dimensions of the compartment are described in detail in the following sections.

\section{$18 \quad 2.1$ Overview, dimensions and coordinate system}

19 The internal dimensions of the experimental compartment were approximately $4.7 \mathrm{~m}$ (depth), $21.0 \mathrm{~m}$ (length), and $2.85 \mathrm{~m}$ (height). In places there were protrusions into this space due to beams, columns and fittings. The compartment along with details of these protrusions are presented in Figure 1 in (a) plan and (b) section. The origin of the coordinates system used to describe locations within and around the compartment is in the rear left corner of the compartment as viewed from the outside looking in (refer to Figure 1). The average floor to ceiling height prior to installation of a false floor (described later) was $2850 \mathrm{~mm}$. This is not inclusive of a $100 \mathrm{~mm}$ deep layer of combustible cork insulation covering approximately $60 \%$ of the ceiling. This layer was on the right-hand side of the compartment as shown in Figure $1 b$. 


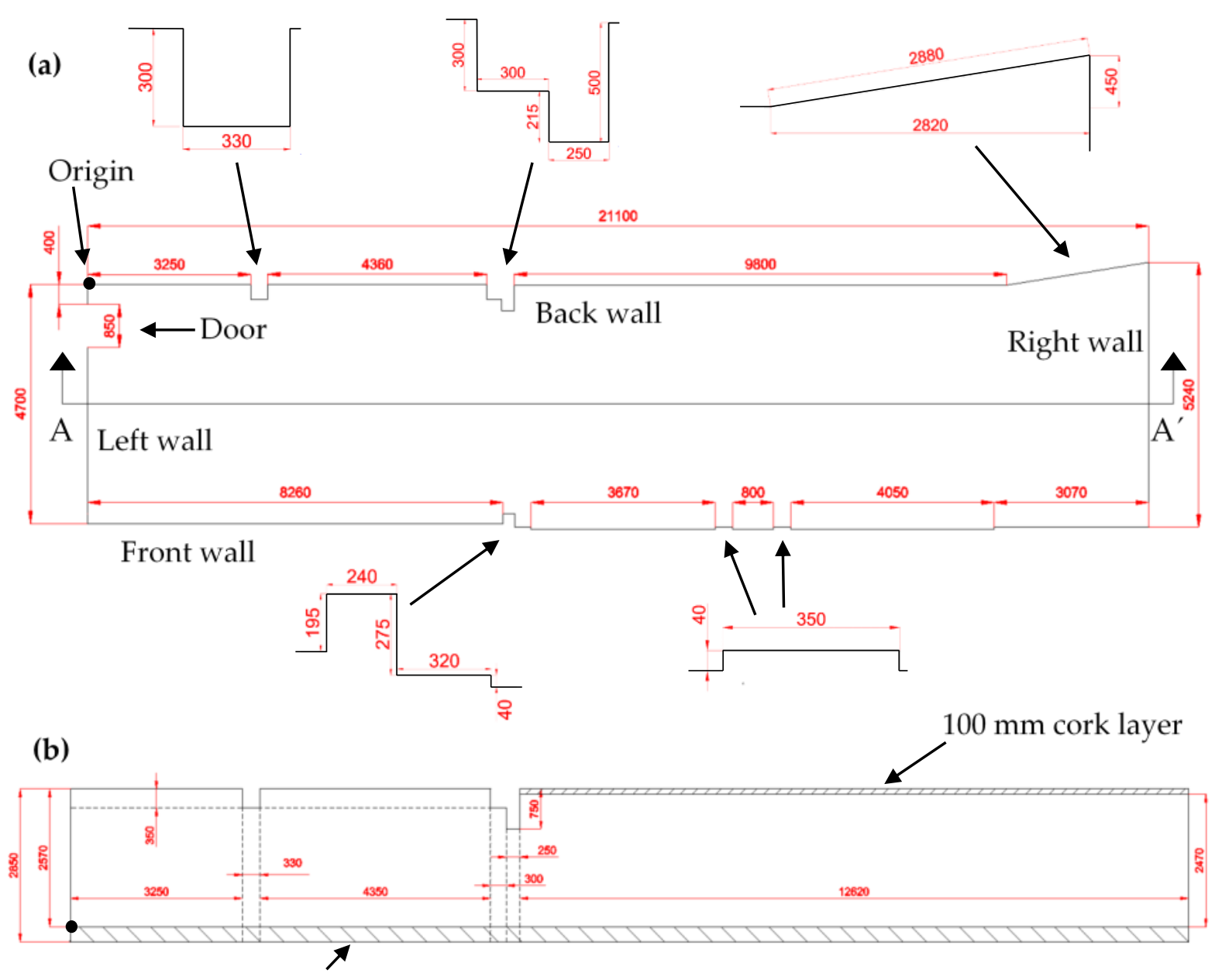

$280 \mathrm{~mm}$ false floor system

Figure 1. (a) The central diagram shows the floor plan of the compartment with overall shape irregularities. (b) Front view, section A-A': Dashed lines indicate positioning and dimensions of concrete columns and beams against back wall. The layer of cork and false floor are represented as hatched areas.

It is believed that, when the building was in use, this large open space originally corresponded to two different office rooms separated by a partition where the soffit beam is located. The two spaces were likely to be built in different stages, thus explaining the presence of cork insulation only in a fraction of the open space. It should be noted that cork is sometimes used as interior insulation in South Europe.

\subsection{Positioning and dimensions of the openings}

The primary openings were formed by five windows of varying dimensions, located along the front wall of the compartment. The positioning and dimensions of these windows are shown in Figure 2. There was one further opening formed by a door. This door was initially closed, however, it was opened during the test to encourage a concurrent flow through the fire and over the fuel bed, and thus encourage a more rapid fire growth. The position of this door is shown in Figure 1(a) and Figure 5 (c). The door opening was $0.85 \mathrm{~m}$ wide and $1.72 \mathrm{~m}$ 
1 high. All other original openings to the compartment were sealed and remained so 2 throughout the test.

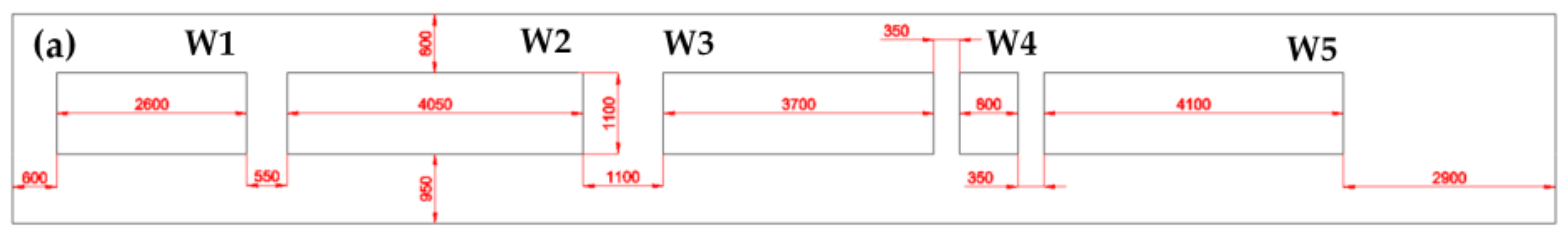

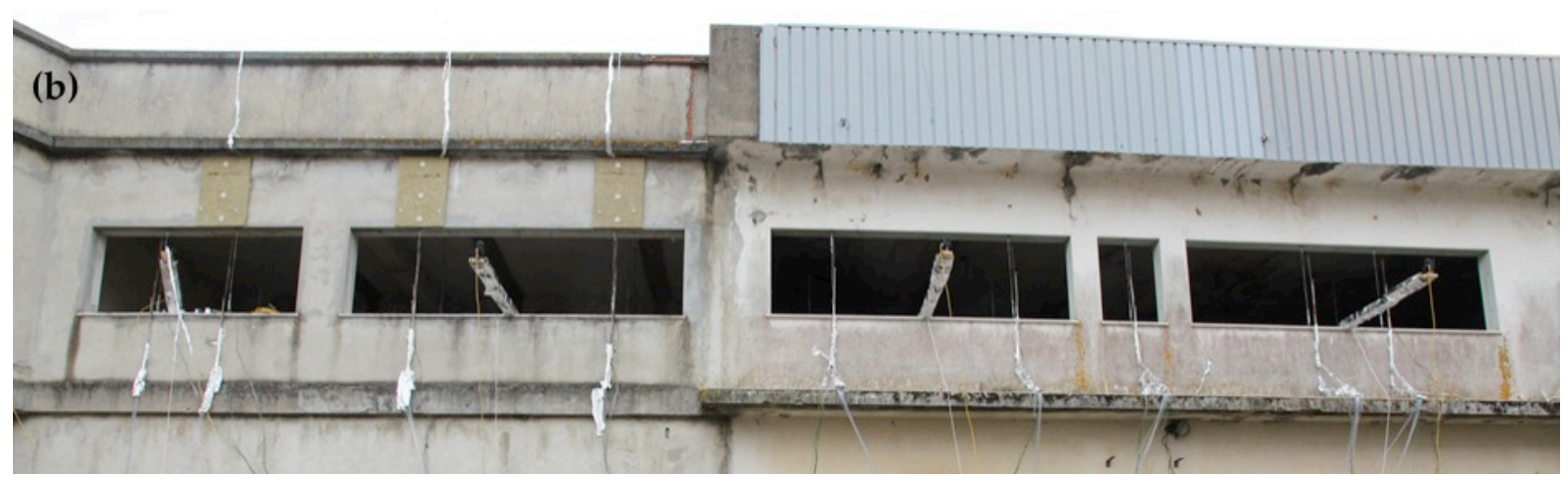

Figure 2. Elevation of the front wall as viewed from outside the compartment. (a) Sketch with location and dimensions of the windows. (b) Picture of the external view of the compartment. External Thin Skin Calorimeters (TSCs) are present on the façade above windows 1 and 2.
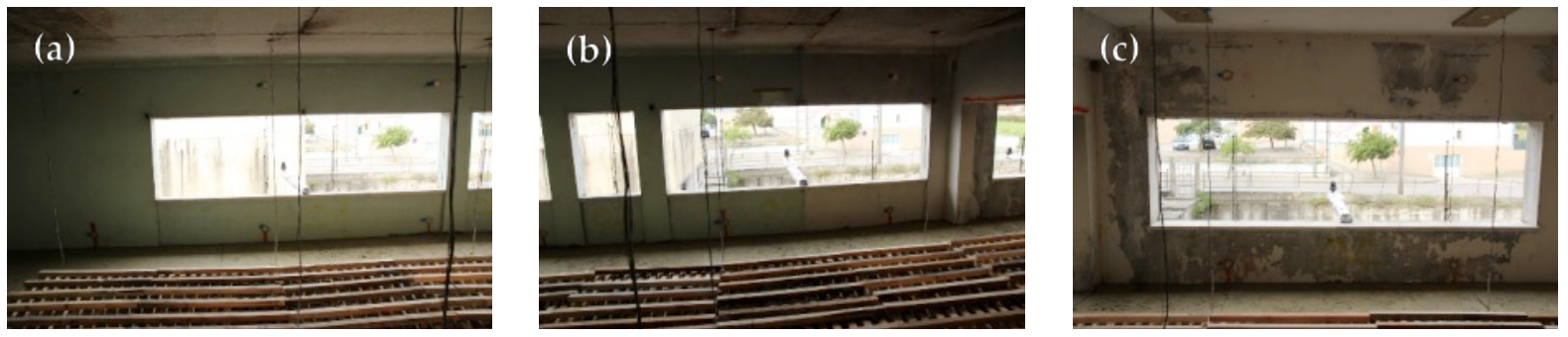

Figure 3. View of the openings W5 (a), W4 and W3 (b) and W2 (c) from inside the compartment. Internal TSCs are visible above and below the openings.

\subsection{Floor plan and floor system}

The dimensions of the floor of the compartment are shown in plan in Figure 1. A false floor system was designed to enable mass loss measurements whilst maintaining a level floor throughout the compartment. The total height of this false floor system was $280 \mathrm{~mm}$. The floor layer consisted, from top to bottom, of $100 \mathrm{~mm}$ of ROCKWOOL CONLIT ${ }^{\mathrm{TM}}$, a $10 \mathrm{~mm}$ plasterboard, and a $20 \mathrm{~mm}$ particleboard. When supported by a mass loss scale, the floor system was attached to a wooden frame that supported the floor $50 \mathrm{~mm}$ above the surface of a $100 \mathrm{~mm}$ deep mass loss scale. The frame system enabled passage of air beneath the floor and all around the mass loss scales in order to insulate and provide cooling. Elsewhere, the floor layer was supported by evenly distributed feet consisting of $50 \mathrm{~mm}$ of ROCKWOOL CONLIT $^{\mathrm{TM}}$ and $100 \mathrm{~mm}$ deep masonry bricks, again to allow air to circulate beneath. The global height coordinate $\mathrm{z}=0.0 \mathrm{~m}$ is level with the top of the false floor. Mass loss scales supported floor platforms with dimensions of $1.2 \mathrm{~m} \times 2.4 \mathrm{~m}$. The distribution of floor 
1 platforms is shown in Figure 4. The final compartment effective height was thus $2570 \mathrm{~mm}$ in

2 the area without cork and $2470 \mathrm{~mm}$ in the area with cork.

\section{$3 \quad 3$ Description of the sensor arrays}

4 A large number of sensors were provided within the experimental compartment and on the 5 external façade. These were designed with the aim of characterising the fire environment at a 6 spatial resolution that enables the benchmarking of tools and or methodologies developed by 7 the RFSDTB project, while at the same time considering the physical and time constraints 8 implied by working within an existing, partially derelict building. The measurements 9 provided by this instrumentation are subject to experimental errors, which have generally 10 been described in detail in the preceding experimental series - the Edinburgh Tall Building 11 Tests [22] and references within. The present test will be subject to the same error analysis conducted for all instrumentation and described in [22], but given that the focus here is to describe the characteristics of the fire and not to deliver a detailed quantitative analysis, the reader is referred to [22] to determine the errors associated to each instrument. Where new corrections are applied or new instrumentation is used, these are presented within each particular section below.

\section{$17 \quad 3.1$ Gas-phase temperature}

$181.5 \mathrm{~mm}$ bead K-type thermocouples were used to establish the spatial and temporal gas-phase 19 temperature fields inside the compartment and in each of the openings. A total of 24 20 thermocouple trees, in three rows of eight trees, with each tree containing eight thermocouples 21 were evenly spaced throughout the interior of the compartment. Each tree had thermocouples at $0.77,1.07,1.37,1.67,1.87,2.07,2.27$ and $2.42 \mathrm{~m}$ above false floor level $(\mathrm{z}=0.0 \mathrm{~m})$. The spacing and locations of these internal trees are shown in Figure 4a. A further nine thermocouple trees were located in the window openings. Each of these trees contained five thermocouples at heights $0.15,0.35,0.55,0.75$, and $0.9 \mathrm{~m}$ above the window ledge, which corresponds to heights $0.82,1.02,1.22,1.42$ and 1.57 above the false floor level $(\mathrm{z}=0.0 \mathrm{~m})$. The locations of these trees are shown in Figure $4 b$. 
(a)

Length [mm]

$0 \quad 1000 \quad 2000 \quad 3000 \quad 4000 \quad 5000 \quad 6000 \quad 7000 \quad 8000 \quad 9000 \quad 100001100012000130001400015000160001700018000190002000021000$

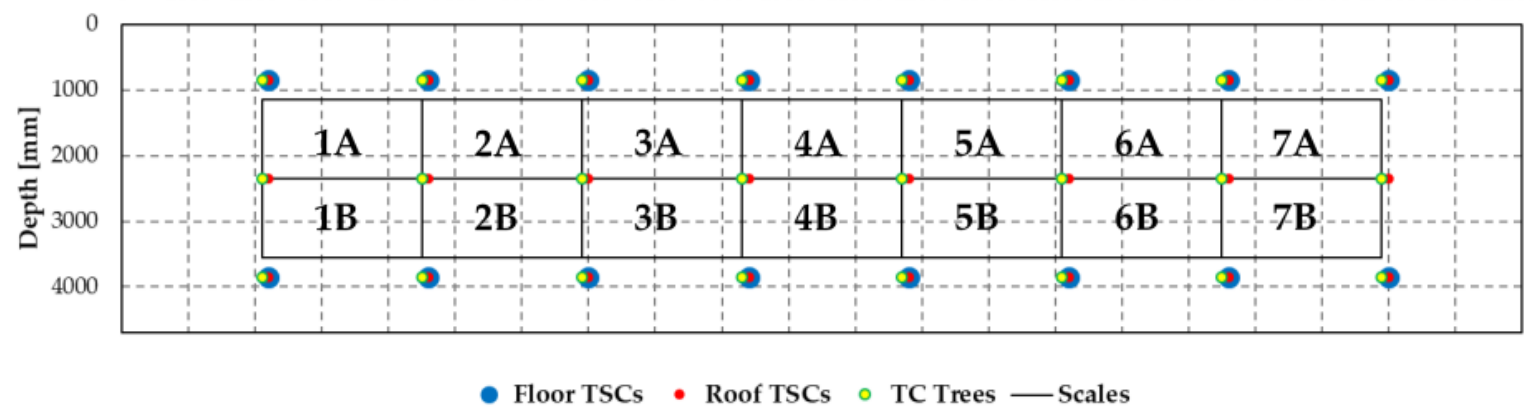

(b)

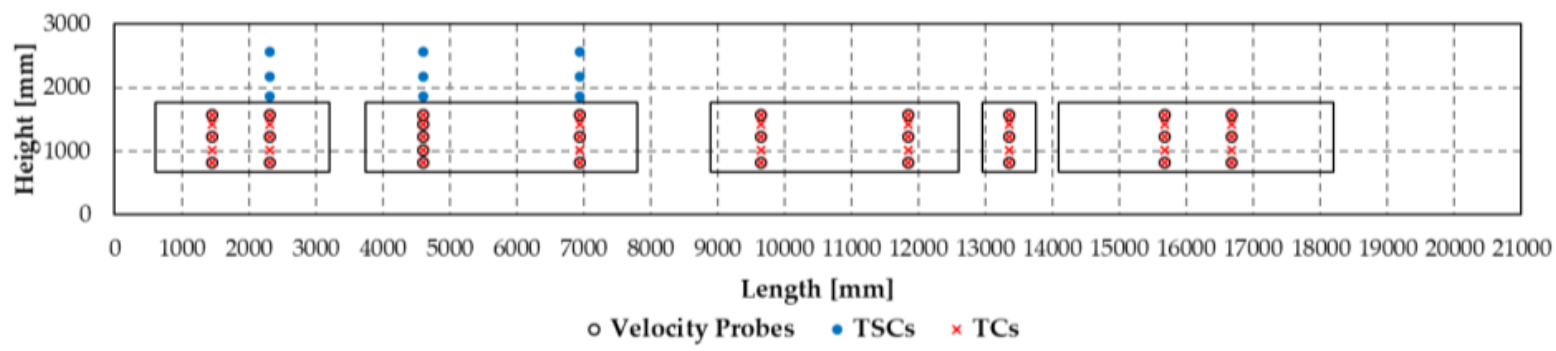

Figure 4. (a) Plan diagram showing floor, ceiling, gas-phase sensor locations and platform

$(1 \mathrm{~A}-7 \mathrm{~B})$ outlines. (b) Elevation diagram showing the window and façade sensor locations. The origin is consistent with the origin shown in Figure 1.

$5 \quad 3.2$ Incident radiant heat flux

6 As per previous experiments in the RFSDTB project [22], thin skin calorimeters (TSCs) were used to quantify incident radiant heat flux to solid surfaces. A total of 93 TSCs were located on all internal surfaces of the compartment, with further nine mounted in three columns of three gauges on the façade above windows 1 and 2. The layout of these TSCs are shown in Figure 5. The external TSCs are shown in Figure $7 \mathrm{~b}$.

The TSCs comprised a $10 \mathrm{~mm}$ diameter, $0.5 \mathrm{~mm}$ thick $304 \mathrm{~b}$ stainless steel plate, with a KXtype thermocouple welded to the centre of the unexposed face. The plate was embedded in a $80 \mathrm{~mm}$ diameter, $25 \mathrm{~mm}$ deep Superwool ${ }^{\circledR}$ HT disc. The thermocouple wires pass through the Superwool ${ }^{\circledR}$ HT and exit through the rear. The design was such that a corresponding hole could be cored from the compartment wall, ceiling or floor and the Superwool@ HT with TSC imbedded inserted, leaving the TSC flush with the surface of the wall, floor or roof. The calibration of these gauges, calculation methodology and associated error analysis are given by Hidalgo et al. [24]. 
(a)

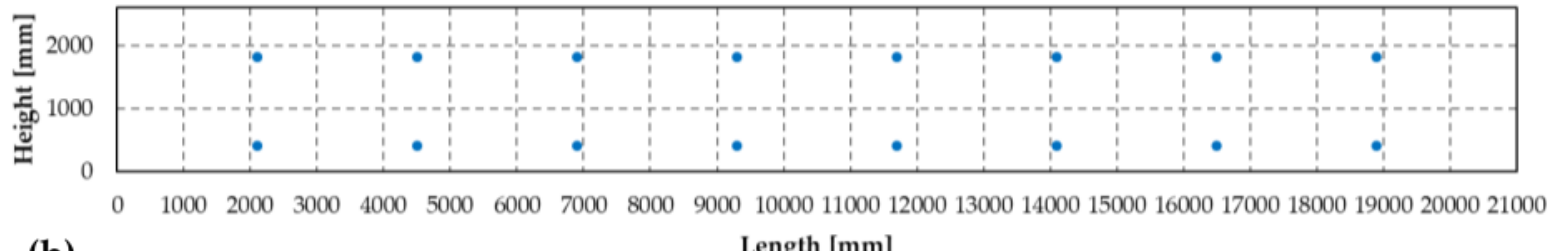
(b) Length $[\mathrm{mm}]$

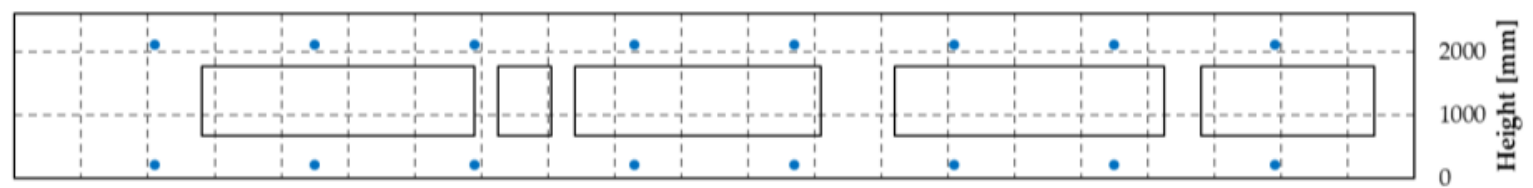
$21000200001900018000170001600015000140001300012000110001000090008000 \quad 7000600050004000300020001000 \quad 0$ Length $[\mathrm{mm}]$

(c)

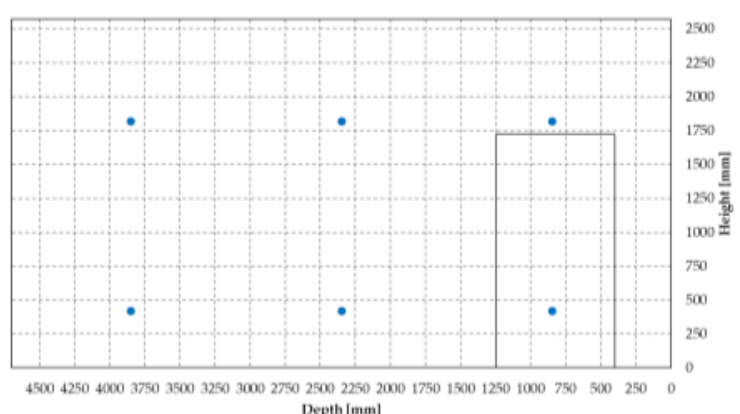

(d)

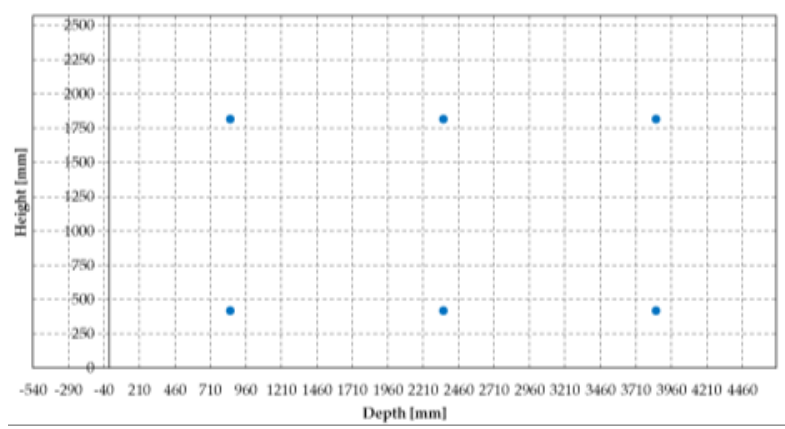

Figure 5. Diagram showing TSC locations as viewed from the inside of the room on (a) back wall, (b) front wall, and (c) left-end wall and (d) right-end wall.

\section{$4 \quad 3.3$ Mass loss}

5 A total of 14 scales were distributed beneath the fuel bed to measure mass loss from the wood 6 cribs used as the design fuel load. The scales were a bespoke design for this test, designed, constructed and installed by LEVANTINA DE PESAJE LABORATORIO, S.L.. Each scale was

$81 \mathrm{~m} \times 1 \mathrm{~m} \times 0.1 \mathrm{~m}$ high and supported a $1.2 \mathrm{~m} \times 2.4 \mathrm{~m}$ false floor platform. The arrangement of these platforms and installation are shown in Figure 4a and in Figure 6, respectively. The maximum load capacity of each scale was $300 \mathrm{~kg}$ with an expected accuracy in the reading of $\pm 20 \mathrm{~g}$. The scales were calibrated on-site before the test. 

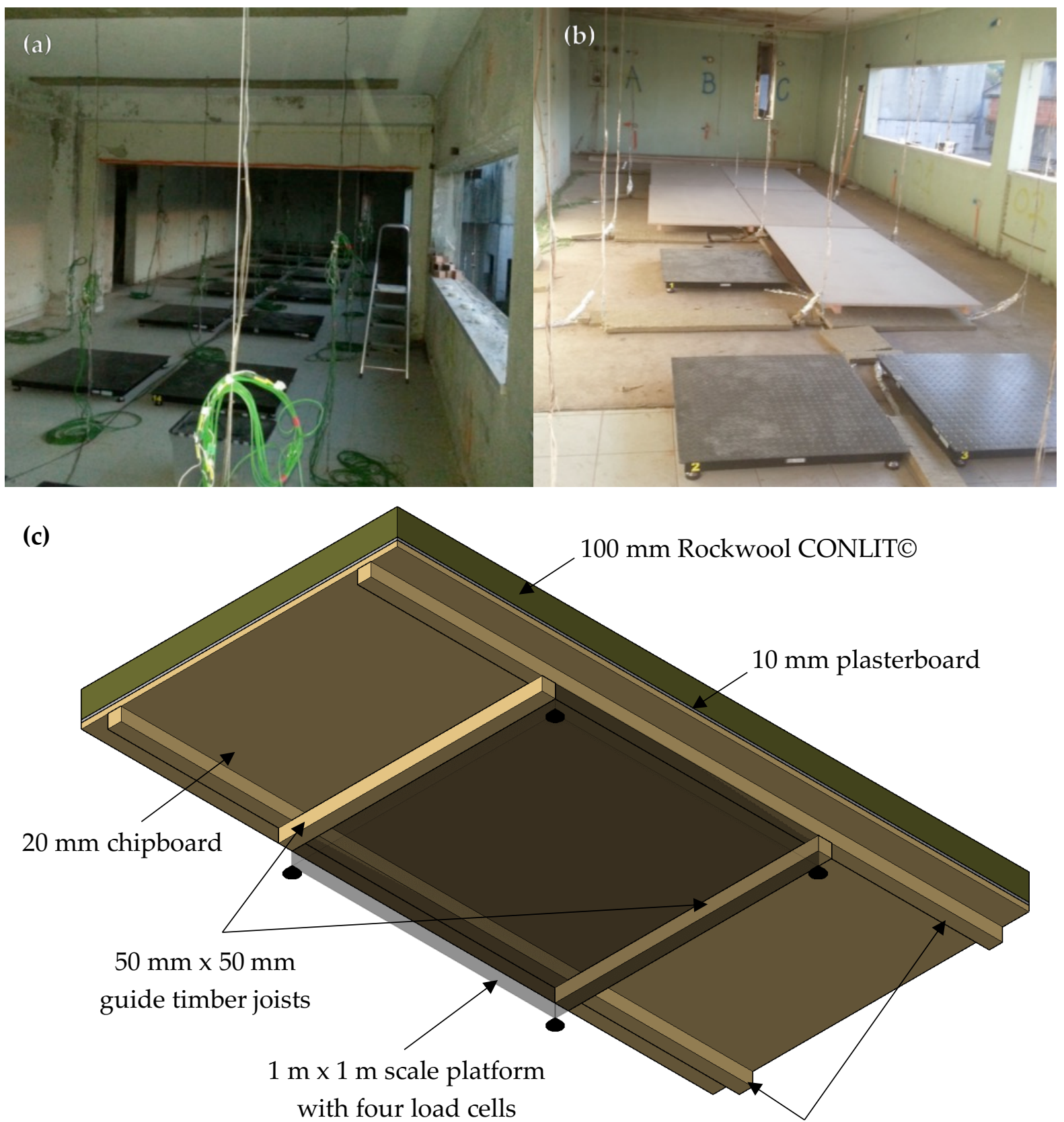

$50 \mathrm{~mm} \times 50 \mathrm{~mm}$ support timber joists

Figure 6. (a) View of the floor from the left end of the compartment, with all the scales in place ready to hold the false floor platforms. (b) View of the floor on the right end of the compartment, with some scales holding the $1.2 \mathrm{~m} \times 2.4 \mathrm{~m}$ platforms for the false floor. (c) Sketch of the false floor system (view from the bottom)

\subsection{Gas flow velocity at the openings}

A total of 29 bi-directional velocity probes [25] were distributed between each of the windows to characterise gas in- and out-flow. The locations of the probes corresponded to the thermocouple trees located there and sit above the external edge of the window sill. Each thermocouple tree location had three corresponding velocity probes except for one which had five velocity probes in window 2 . Where three probes were present, they corresponded in height to the upper, middle and lower thermocouples of the window trees (i.e. $0.82 \mathrm{~m}, 1.22 \mathrm{~m}$, 
and $1.57 \mathrm{~m}$ from the false floor). The single location with five probes had a probe at each of the

2 heights of the thermocouples in the corresponding tree (i.e. $0.82 \mathrm{~m}, 1.02 \mathrm{~m}, 1.22 \mathrm{~m}, 1.42 \mathrm{~m}$, and

$3 \quad 1.57 \mathrm{~m}$ from the false floor). The specific positioning of each probe relative to the windows is

4 shown in Figure $4 \mathrm{~b}$. A representation of the system used to install the pressure probes is

5 shown in Figure 7.

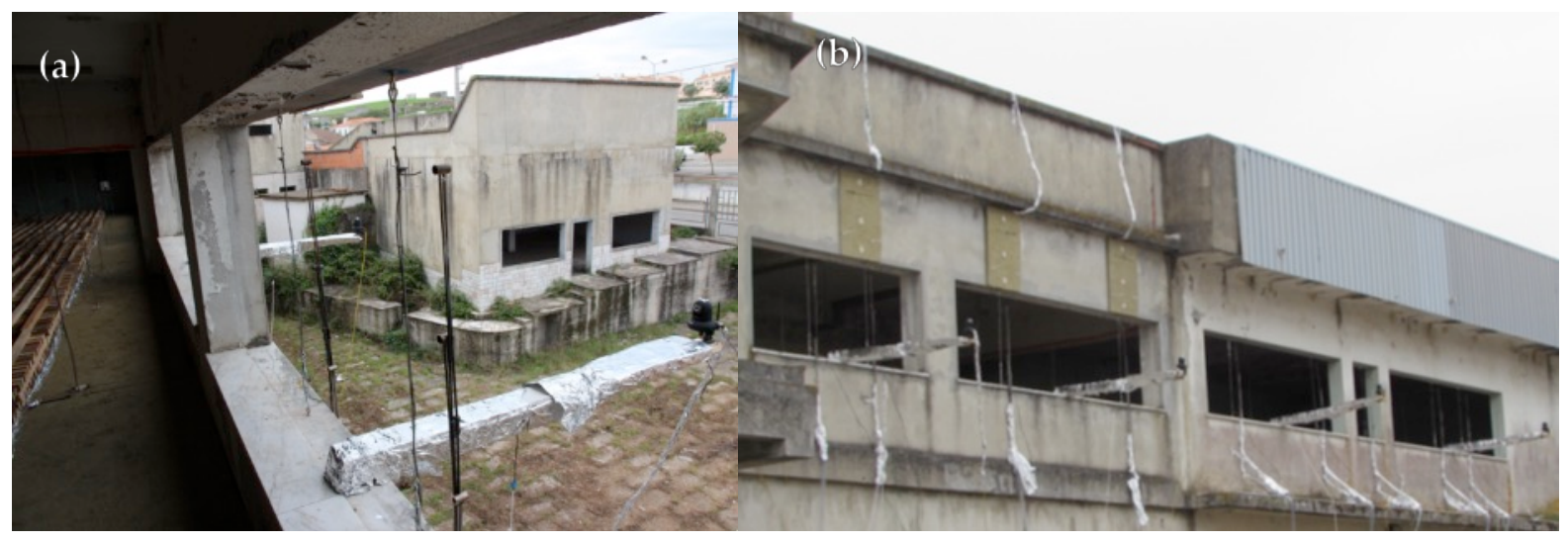

Figure 7. (a) Window 1 showing the arrangement of bi-directional velocity probes and the cantilever system for the external network cameras. (b) View of the windows with bidirectional velocity probes and external network cameras, and the façade with thin skin calorimeters above windows 1 and 2.

The bi-directional velocity probes were connected to differential pressure transducers. The set probe-transducer has recently been calibrated in a wind tunnel facility. Detailed results from these calibrations are presented by Gupta et al. [26]. The relation between velocity and voltage output from the transducers is shown in Figure 8 below.

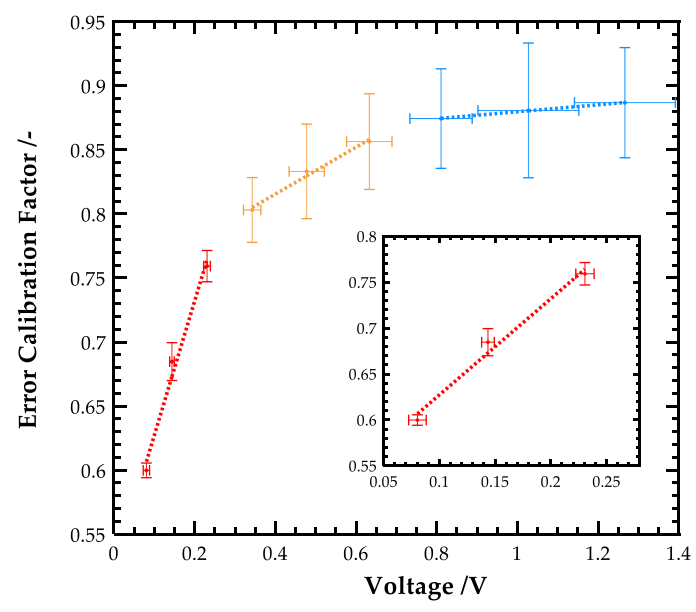

Figure 8. Correction factor for the bi-directional velocity probe and differential pressure transducer setup [26].

\subsection{Video imaging}

A total of eight network cameras were employed to capture video footage of the experiment. A camera was embedded in each of the end walls looking along the length of the compartment. To enable analysis of the fire and burnout front position, cameras were also placed to look in through each of the four large windows (refer to Figure $7 \mathrm{~b}$ ). These cameras 
1 were mounted to an insulated wooden beam cantilevered approximately $2 \mathrm{~m}$ out from the

2 corresponding window sill. Two final cameras were positioned on the external façade of the

3 compartment looking along the face of the openings. These cameras were positioned at mid

4 window height in order to provide visual confirmation of the smoke layer height and

5 evolution of the fire spread and burnout fronts. Further to the network cameras, a digital video

6 camera and a thermal imaging camera were setup on the roof of a building in front of the

7 experimental compartment to provide an overview of events inside the compartment and

8 fully capture any smoke and flames emerging from the compartment front openings.

\section{$9 \quad 3.6$ Data logging}

10 Data logging was performed by two Agilent 34980A Switch/Measure Units, equipped with

11 34925A 40/80 Channel Optically Isolated FET Multiplexer modules. Each data logger was

12 fitted with a 4-wire RTD in order to provide an external reference temperature for the

13 thermocouples and connected via LAN cable to a unique PC to ensure that any computer

14 issues had minimal impact on the amount of data recorded. Two PCs were assigned to log

15 data from eight network cameras and a laptop was provided to record data from the thermal

16 imaging camera. A final PC was associated to a bespoke data logging system for the mass loss

17 scales. The bespoke system was designed and installed by LEVANTINA DE PESAJE

18 LABORATORIO, S.L.

\section{Fuel, ignition and opening factor}

20 The fuel used in this experiment was wood cribs of Pinus Pinaster, with an assumed density of $510 \mathrm{~kg} \cdot \mathrm{m}^{-3}$ and a heat of combustion of $18 \mathrm{MJ} \cdot \mathrm{kg}^{-1}$ provided by CIBSE Guide E to estimate fire loads in terms of the equivalent weight of wood [27]. Wood cribs were used, as in many other historical fire experiments, as it enables an idealised, simplified and evenly distributed fuel source. The intended fuel load was approximately $420 \mathrm{MJ} \cdot \mathrm{m}^{-2}$, average design fuel load for an office according to EN 1991-1-2 [13]. The fuel bed was comprised of three full layers and one-half layer of Pinus Pinaster sticks. Each stick was $1.2 \mathrm{~m}$ long with a $5 \mathrm{~cm} \times 5 \mathrm{~cm}$ cross section. In full layers, sticks were spaced at $5 \mathrm{~cm}$ thus each full layer was comprised of 10 sticks per metre length of fuel bed. In the half layer, sticks were spaced at $15 \mathrm{~cm}$ giving 5 sticks per metre run. The overall fuel bed size was $16.8 \mathrm{~m}$ long x $2.4 \mathrm{~m}$ wide as shown in Figure 9 . The total amount of fuel was calculated using the total floor area of the compartment. 


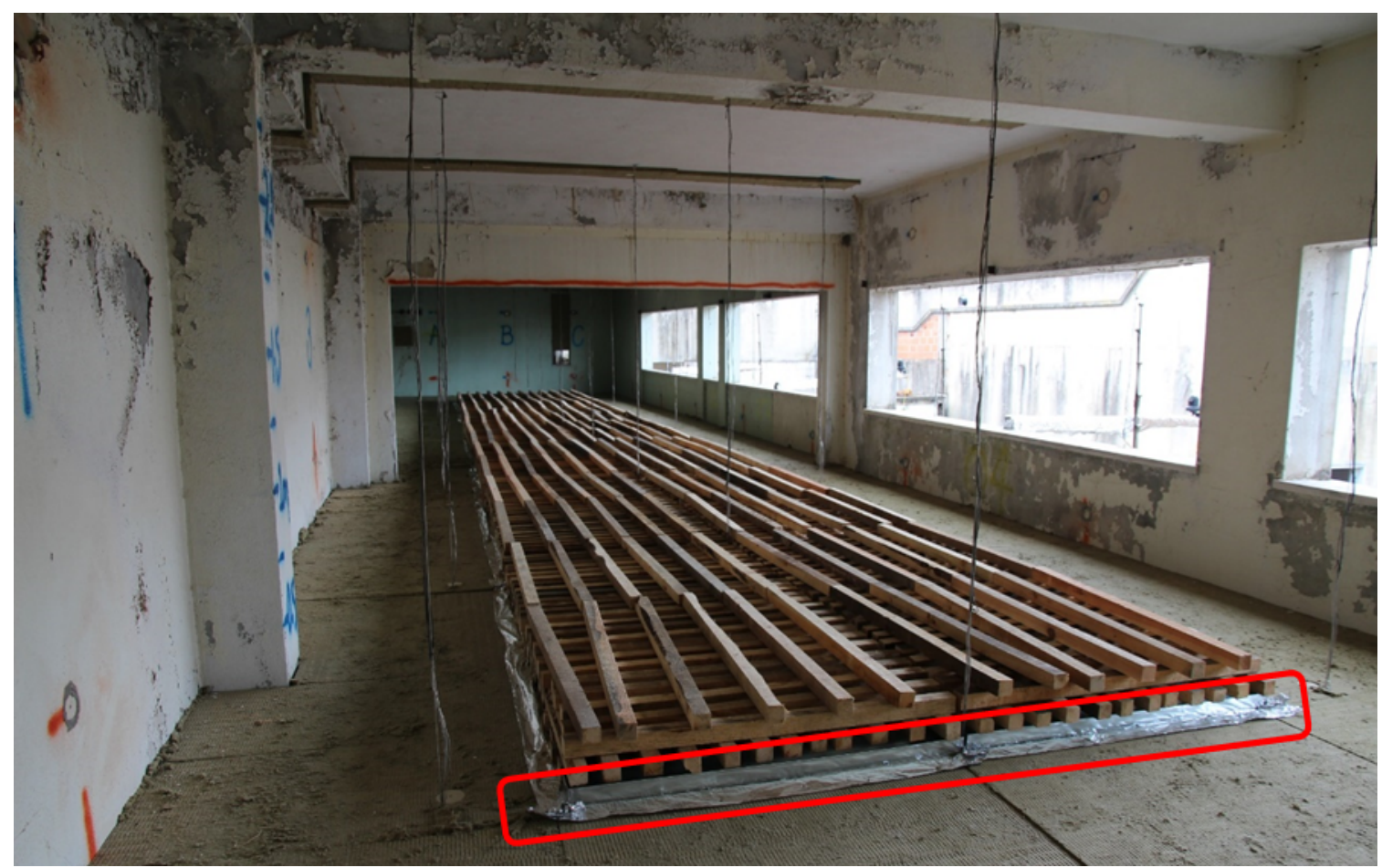

2 Figure 9. The image shows the arrangement of the beams and columns protruding into 3 the experimental volume. It shows the fuel bed with the ignition fuel tray highlighted in red.

5 Moisture content measurements taken on the day of the experiment suggest an average 6 moisture content of the individual sticks of $19 \% \pm 6 \%$. The average moisture content for the crib measurements along the approximated crib weight on each platform is shown in Table 1 .

Table 1. Estimated mass and moisture content measurements for the wood cribs on each platform. Three data points per platform were taken for moisture measurements.

\begin{tabular}{|c|c|c|c|c|c|c|}
\hline $\mathbf{1 A}$ & $\mathbf{2 A}$ & $\mathbf{3 A}$ & $\mathbf{4 A}$ & $\mathbf{5 A}$ & $\mathbf{6 A}$ & $\mathbf{7 A}$ \\
$153.7 \mathrm{~kg}$ & $158.1 \mathrm{~kg}$ & $166.6 \mathrm{~kg}$ & $167.9 \mathrm{~kg}$ & $174.3 \mathrm{~kg}$ & $166.5 \mathrm{~kg}$ & $158.7 \mathrm{~kg}$ \\
$17 \% \pm 2 \%$ & $20 \% \pm 5 \%$ & $22 \% \pm 13 \%$ & $13 \% \pm 1 \%$ & $15 \% \pm 1 \%$ & $16 \% \pm 2 \%$ & $15 \% \pm 3 \%$ \\
\hline $\mathbf{1 B}$ & $\mathbf{2 B}$ & $\mathbf{3 B}$ & $\mathbf{4}$ & $\mathbf{5 B}$ & $\mathbf{6 B}$ & $\mathbf{7 B}$ \\
$158.0 \mathrm{~kg}$ & $170.8 \mathrm{~kg}$ & $164.1 \mathrm{~kg}$ & $167.2 \mathrm{~kg}$ & $171.1 \mathrm{~kg}$ & $159.8 \mathrm{~kg}$ & $169.7 \mathrm{~kg}$ \\
\hline $18 \% \pm 1 \%$ & $23 \% \pm 12 \%$ & $20 \% \pm 4 \%$ & $28 \% \pm 13 \%$ & $18 \% \pm 4 \%$ & $16 \% \pm 2 \%$ & $19 \% \pm 1 \%$ \\
\hline
\end{tabular}

In addition to the wood crib, the only other fuel source available in the compartment was the $100 \mathrm{~mm}$ cork layer attached to the ceiling on the right-hand side of the compartment (Figure $1 b)$. The cork layer was an energy efficiency feature of the building. It was decided not remove it in order to provide a different boundary condition which could induce a change in fire mode due to lower heat losses or heat release contribution.

Thermogravimetric studies on the wood and cork were applied to characterise the volatile content and yield residue of both materials. These were tested with a heating rate of $20^{\circ} \mathrm{C} . \mathrm{min}^{-}$ ${ }^{1}$ in three conditions: air, nitrogen, and air after testing in nitrogen. The normalised mass and derivative of the normalised mass versus temperature are presented in Figure 10 below. In nitrogen tests, it is shown that both wood and cork provide a char yield of approximately $20 \%$. 
1 The char appears to oxidise above $450^{\circ} \mathrm{C}$, whereas the pyrolysis reactions are approximately 2 observed within $200-400^{\circ} \mathrm{C}$ for wood and $250-450^{\circ} \mathrm{C}$ for cork. This indicates that pyrolysis and 3 condensed-phase oxidation reactions occur within a very similar temperature range for cork 4 and wood nevertheless, for both materials, pyrolysis and char oxidation occur in different 5 temperature domains. Thus, the wood and the cork are identified as very similar charring 6 burning fuels. Additionally, these fuels show similar heat release rate per unit area (120 - 206 $7 \quad \mathrm{~kW} \cdot \mathrm{m}^{-2}$ for cork [28] and 54-177 for Radiata Pine [29]). The differences between the cork and 8 wood fuel are the exposed surface area (much larger in the wood crib) and the material density 9 and thermal conductivity $\left(160 \mathrm{~kg} \cdot \mathrm{m}^{-3}\right.$ for cork and $430-640 \mathrm{~kg} \cdot \mathrm{m}^{-3}$ for pine; $0.043 \mathrm{~W} \cdot \mathrm{m}^{-1} \cdot \mathrm{K}^{-1}$ for cork and 0.112-0.147 W. $\mathrm{m}^{-1} . \mathrm{K}^{-1}$ for pine according to Table A.28 in [30]). Therefore, a lower burning rate is expected from the cork, however, the lower thermal inertia of cork (insulation) implies a faster ignition and flame spread [31, 32].
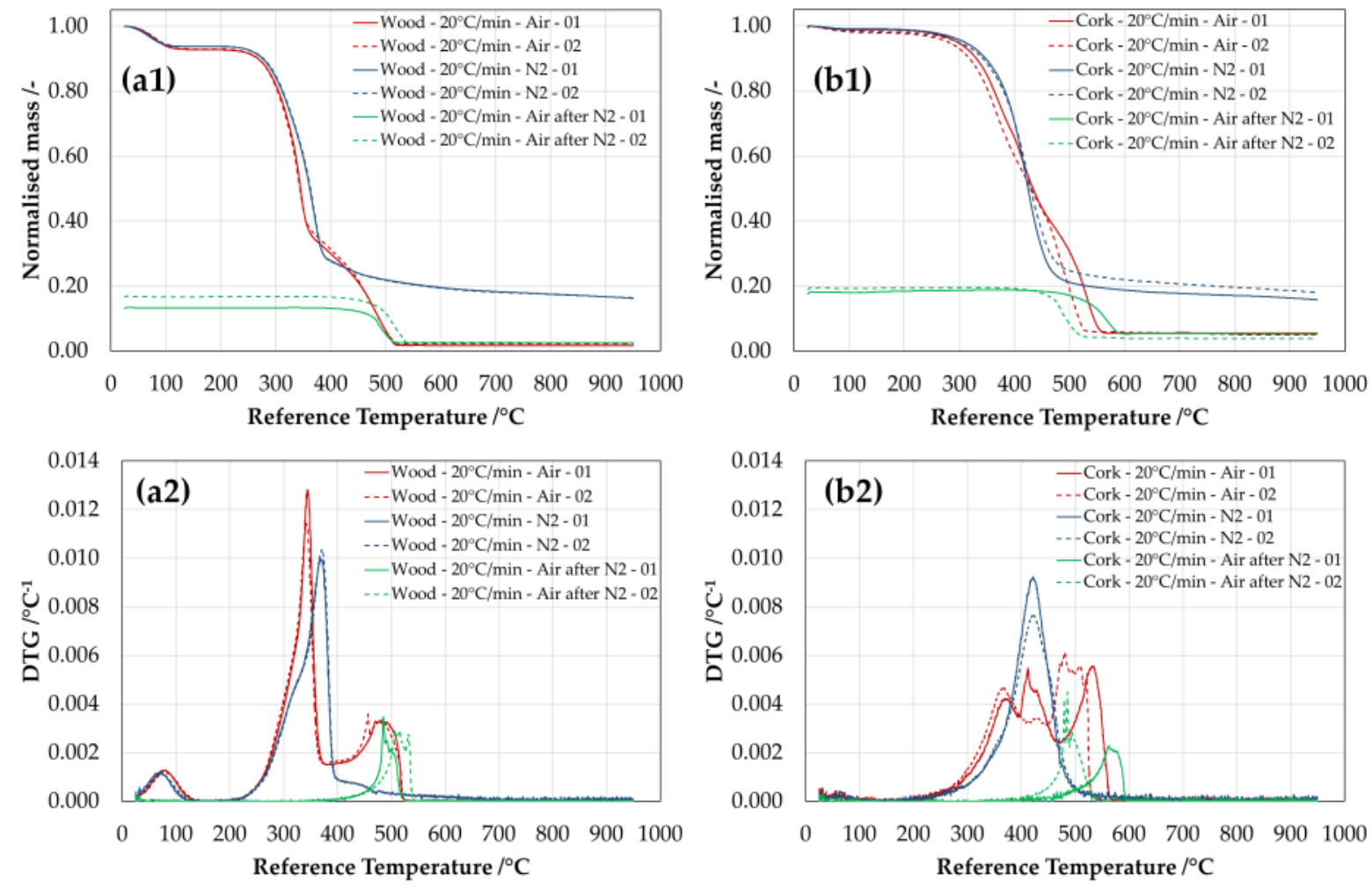

Figure 10. Thermogravimetric analyses of wood (a) and cork (b) used in the test. Plots on indicate the derivative of the normalised mass versus temperature. Tests were carried out in air, nitrogen, and in air after decomposition in nitrogen at $20^{\circ} \mathrm{C} . \mathrm{min}^{-1}$.

Ignition of the wood crib was achieved through a $2.4 \mathrm{~m}$ line fire. A mixture of 5 litres of kerosene and 0.5 litres of diesel fuel was placed in a $2.4 \mathrm{~m}$ long $\times 10 \mathrm{~cm}$ wide and $5 \mathrm{~cm}$ high metal tray. This tray was placed at the start of the crib in place of the lowest two sticks, shown highlighted in Figure 9. A blow torch was applied to the liquid fuel mixture until ignition was achieved.

Table 2 shows the inverse of the opening factor calculated for the compartment under different assumptions. Table 2 uses three different calculation methods. The first is the 
conventional method used by Thomas and Heselden [11], while the second and third columns use alternative methods that either include the cork or exclude all fuel in the calculation of $A_{T}$. For all cases, it is shown that the inverse of the opening factor is below $10 \mathrm{~m}^{-0.5}$, where Regime II fires are generally identified. The conditions were thus set to allow the exploration of the fire dynamics of Modes 2 and 3. The right hand side of the compartment (Figure 1) has slightly lower inverse ventilation factors, leading to the expectation that the fire will remain well within Regime II as it transitions towards the area with the cork. It is important to note that the inverse opening factor was not defined for an open floor plan geometry like the one presented here, therefore these calculations are only presented for reference. The theoretical underpinnings of concepts such as fully developed fires, ventilation limited firers, the Compartment Fire Framework or flashover have been extracted from experimental studies where the compartment is sufficiently small that the fire is allowed to spread across the fuel on the floor of the compartment until it reaches a static boundary $[4,11]$. While flashover can occur before the fire has reached its bounds all other terms have been defined using a fire where the burning fuel has static boundaries.

Table 2. Estimated opening factor for the compartment under different assumptions such as considering the compartment as a whole or separated sections divided by the central $500 \mathrm{~mm}$ deep beam dividing the two areas with different ceilings. The right hand column is not a conventional way of presenting the inverse opening factor and it is just presented to show that even with this bounding value the fire will remain within Regime II.

\begin{tabular}{|l|l|c|c|}
\hline \multicolumn{1}{|c|}{ Compartment } & $\begin{array}{c}\text { Inverse opening } \\
\text { factor } \phi^{\prime}=\frac{A_{T}}{A_{w} \sqrt{H}} \\
\left(A_{T} \text { excludes floor }\right. \\
\text { and openings }) \\
/ \mathbf{m}^{-0.5}\end{array}$ & $\begin{array}{c}\text { Inverse opening } \\
\text { factor } \phi^{\prime}=\frac{A_{T}}{A_{w} \sqrt{H}} \\
\left(A_{T} \text { excludes wood }\right. \\
\text { crib and cork } \\
\text { surfaces and } \\
\text { openings } \\
/ \mathbf{m}^{-0.5}\end{array}$ & $\begin{array}{c}\text { Inverse opening } \\
\text { factor } \phi^{\prime}=\frac{A_{T}}{A_{w} \sqrt{H}} \\
\left(A_{T} \text { excludes only }\right. \\
\text { the openings }) \\
/ \mathbf{m}^{-0.5}\end{array}$ \\
\hline $\begin{array}{l}\text { Overall compartment } \\
\text { compartment side }\end{array}$ & 4.6 & 6.4 & 9.5 \\
\hline $\begin{array}{l}\text { Right-hand side } \\
\text { compartment }\end{array}$ & 3.4 & 5.9 & 6.6 \\
\hline
\end{tabular}

\section{Results}

A set of characteristic results that provide an overview of conditions throughout the experiment are presented.

\subsection{Principal events and visual analysis of the evolution of the fire}

After ignition the fire grew at a slow rate, continuing to travel at an apparent constant rate throughout the left-hand side of the compartment. This was visually confirmed with the fire front and burnout front displacing at a slow rate. The flame height was not uniform along the 
1 compartment was opened in order to study whether lateral flow would accelerate the fire 2 front spread velocity. After the door was opened, the computer system shut down, thus 3 interrupting the data logging system. The problem was solved approximately 5 min later, 4 resuming data logging. As the travelling fire approached the beam that differentiated the 5 compartment with and without cork on the ceiling, the fire appeared to grow in size as the 6 flames were apparently larger. After reaching the beam, it was observed that the cork 7 insulation ignited and soon after the flame on the cork spread vigorously. The fire front on 8 the crib then experienced a quick acceleration; soon the whole wood crib on the right-hand 9 side of the compartment was burning. External flaming was then observed. After two minutes 10 manual extinction was applied by the Fire Service due to the potential risk of collapse of the 11 building. Several instances of spalling were observed from the wall linings and beams.

12 A list of the major events observed in the test is provided in Table 3 below. Based on these events and the data obtained from the experiments, five distinct time domains are defined to ease the interpretation of results and fire behaviour. The timeframe for each domain is selected based on the trends observed in the burning rate presented in further sections.

Table 3. List of principal events observed in the test and time domains for analysis.

\begin{tabular}{|c|c|c|}
\hline Event & Time & $\begin{array}{l}\text { Analysis time } \\
\text { domain }\end{array}$ \\
\hline Ignition & $0 \min 0 \mathrm{~s}(13: 10: 47)$ & $\begin{array}{l}\text { Domain I } \\
(0-19 \text { min })\end{array}$ \\
\hline Burnout front starts to develop & $\begin{array}{l}21 \text { min 22s }(13: 32: 09) \\
\text { (estimation) }\end{array}$ & \multirow{2}{*}{$\begin{array}{l}\text { Domain II } \\
\text { (19-152 min) }\end{array}$} \\
\hline Opening of door & $147 \min 57 \mathrm{~s}(15: 18: 44)$ & \\
\hline Generator shut down - data logging stopped & $192 \min 18 \mathrm{~s}(16: 23: 05)$ & \multirow{4}{*}{$\begin{array}{l}\text { Domain III } \\
(152-237 \mathrm{~min})\end{array}$} \\
\hline Generator turned on - data logging resumed & $206 \min 59 \mathrm{~s}(16: 37: 46)$ & \\
\hline Fire front reaches central frame & $224 \min 42 s(16: 56: 09)$ & \\
\hline Ignition spotted on cork ceiling & $228 \min 21 \mathrm{~s}(16: 59: 19)$ & \\
\hline Rapid flame spread on the ceiling & 237 min 11s (17:07:58) & \multirow{3}{*}{$\begin{array}{l}\text { Domain IV } \\
(237-238 \mathrm{~min})\end{array}$} \\
\hline Rapid flame spread of the wood crib & $237 \min 53 s(17: 08: 40)$ & \\
\hline External flaming & $238 \min 0 s(17: 08: 47)$ & \\
\hline Extinction by Fire Service & $241 \min 6 \mathrm{~s}(17: 11: 53)$ & $\begin{array}{l}\text { Domain V } \\
(238-242 \mathrm{~min})\end{array}$ \\
\hline
\end{tabular}

17 Figure 11 shows the different events and stages of the fire captured from the exterior with 18 video and SLR cameras. 

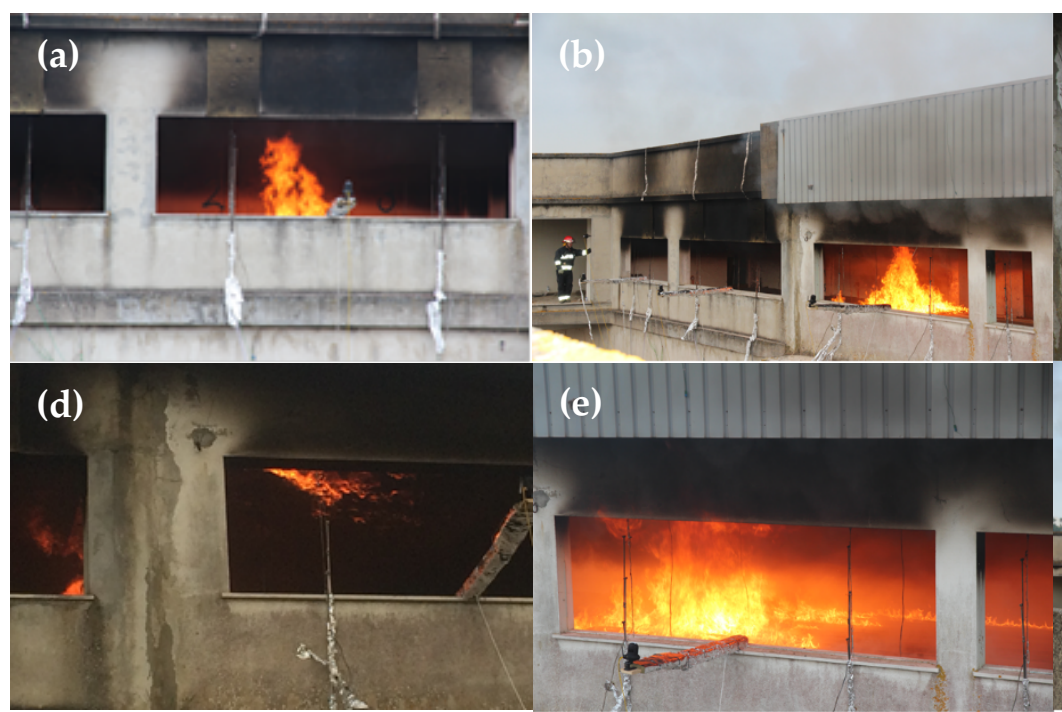

(e)

Figure 11. Sequence of images from the front video and SLR camera. (a), (b) and (c) show the travelling fire mode. (d) shows the ignition and fire spread of the cork insulation. (e) shows transitioning to a "fully-developed" mode as shown in (f).

Using the video footage from the front cameras and a video image processing technique [33], the position of the fire and burnout fronts are estimated for the whole duration of the test (Figure 12a). The length of the fire is calculated as the difference between the positions of these two fronts. Assuming that the fire spread and burned out uniformly along the width of the crib $(2.4 \mathrm{~m}$ ), the length and size (area) of the fire can be estimated (refer to Figure 12b). From the five distinct time domains defined in Table 3, Figure 12 shows clear different growth rates:

- Domain II with $2 \mathrm{~mm} \cdot \mathrm{min}^{-1}\left(0.005 \mathrm{~m}^{2} \cdot \mathrm{min}^{-1}\right)$, corresponding with the definition of Mode $3\left(V_{S} / V_{B O} \approx 1\right)$;

- Domain III with $28 \mathrm{~mm} \cdot \mathrm{min}^{-1}\left(0.067 \mathrm{~m}^{2} \cdot \mathrm{min}^{-1}\right)$, corresponding with the definition of Mode $2\left(V_{S} / V_{B O}>1\right)$; and

- Domain IV with $1686 \mathrm{~mm} \cdot \mathrm{min}^{-1}\left(4.046 \mathrm{~m}^{2} \cdot \mathrm{min}^{-1}\right)$, corresponding with the definition of Mode $1\left(V_{S} / V_{B O} \rightarrow \infty\right)$.

The growth rates for domains I and V are not assessed as for domain I the burnout front was not established yet, whereas for domain $\mathrm{V}$ all the wood crib was burning. It should be noted that the chosen trend lines hide other trends in smaller time scales, e.g. the fluctuations in domain III. Despite the smoothing effects, this approach is preferred for easier interpretation of results.

The transition between Domaine II and Domaine III is not related to the opening of the door. As it can be seen from Figure 12(a) (dotted black lines), the deviation from the parallel line fits can be traced to an earlier time. In contrast, an analysis of the burning rate shows the transition to occur later (see Mass Loss section). The transition point is difficult to determine and quantifying it is beyond the scope of this study. For the purpose of this description, the opening of the door will therefore be used as indicative of the moment of transition. 
(a)

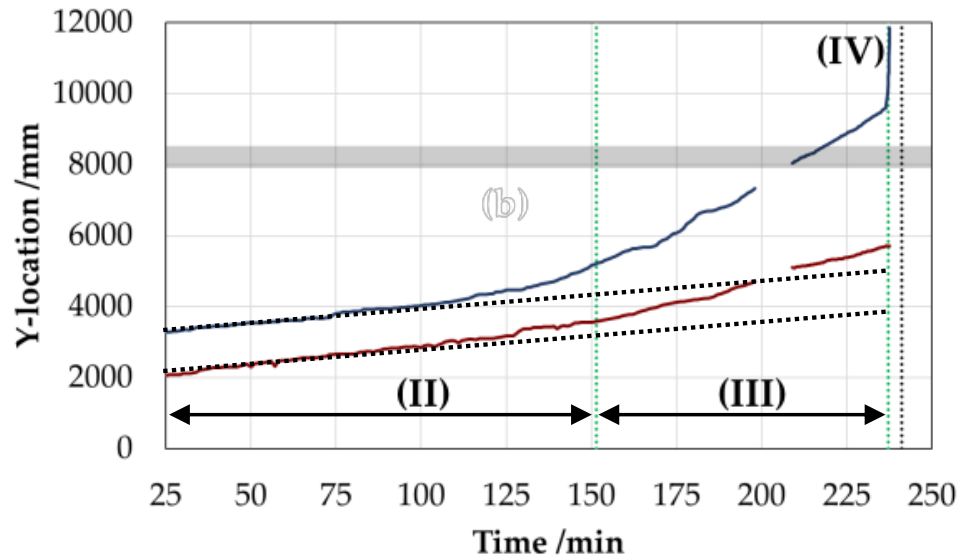

(b)

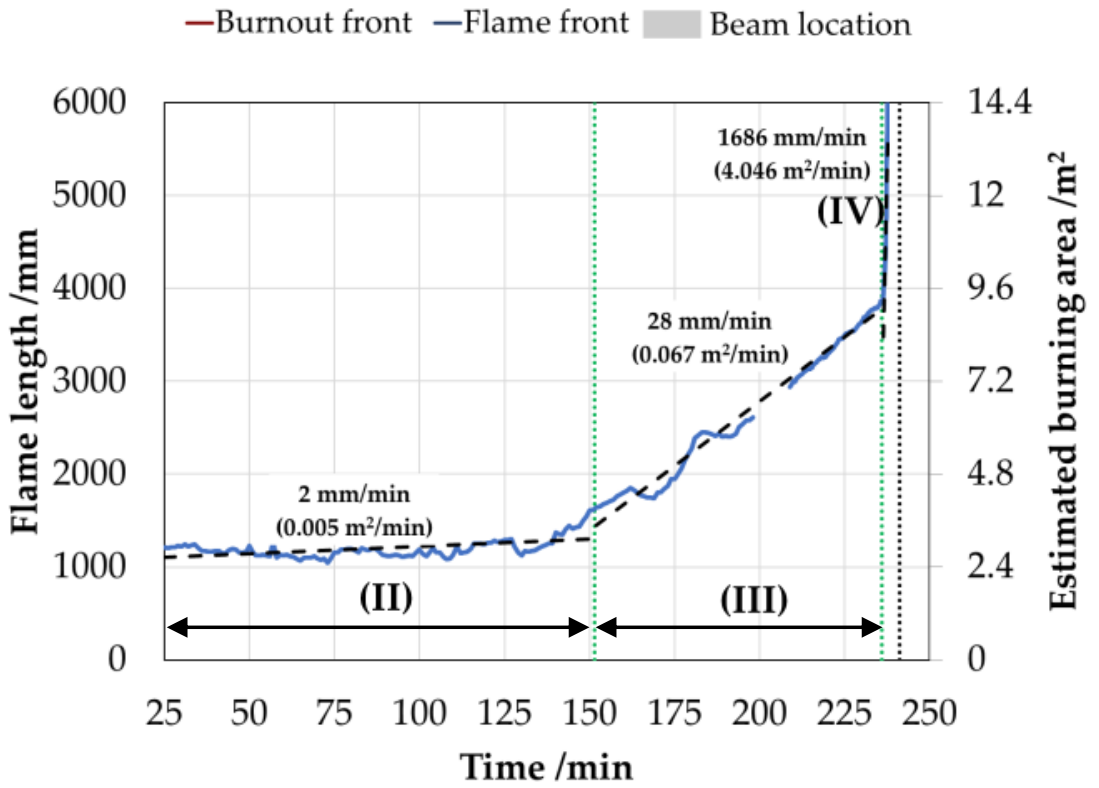

Figure 12. (a) Position of the fire spread and burnout front obtained with image processing techniques using video footage from network cameras located at the windows.

The shading area corresponds to the location of the beam that separates the region of compartment with different ceilings. (b) Estimated length and size of the fire based on 6 the assumption that the fire grows uniformly along the width/depth of the compartment.

\section{$7 \quad 5.2$ Mass loss}

8 Figure 13 shows the normalised readings of each of the 14 scales, with $1 \mathrm{~A}$ and $1 \mathrm{~B}$ 9 corresponding to the ones on the left-hand side of the compartment next to the wall and next 10 to the window, respectively. Wherever possible, the data have been cleaned so that increase 11 of mass due to debris from the cement linings falling onto the scale is minimised. Until 125 12 minutes, it is shown that only the fuel on $1 \mathrm{~A}$ and $1 \mathrm{~B}$ decreases. The mass loss follows a linear 13 decrease, suggesting a steady burning rate. It is also observed that, up to 58 minutes, $1 \mathrm{~A}$ and 14 1B experience similar mass loss, however, the burning rate of $1 \mathrm{~B}$ is slightly higher afterwards. 15 From 125 minutes to 160 minutes, the wood cribs on $2 \mathrm{~A}$ and $2 \mathrm{~B}$ appear to be burning along 16 with $1 \mathrm{~A}$ and $1 \mathrm{~B}$, which burn at a very low rate probably experiencing smouldering. After 170 17 minutes, the wood cribs $1 \mathrm{~A}$ and $1 \mathrm{~B}$ appear to be almost completely consumed; instead, $2 \mathrm{~A}$ 
1 and 2B show a linear decrease, suggesting again a steady burning rate. Although 2A initially 2 shows a lower burning rate, after 160 minutes it appears to be faster than 2B. After 195 3 minutes, the cribs $3 \mathrm{~A}$ and $3 \mathrm{~B}$ start to burn with the same pattern as shown by the previous 4 pair of cribs. It is clearly shown that the slope of $3 \mathrm{~A}$ and $3 \mathrm{~B}$ is larger than the slope of $2 \mathrm{~A}$ and $52 \mathrm{~B}$, and the slope of these is larger than $1 \mathrm{~A}$ and $1 \mathrm{~B}$. $3 \mathrm{~A}$ is also shown to burn much faster than $63 \mathrm{~B}$, presumably due to higher radiant feedback as $3 \mathrm{~A}$ was closer to the wall whereas $3 \mathrm{~B}$ was 7 closer to the window (refer to section 5.4). After 238 minutes the rest of the cribs start to lose 8 mass significantly faster and at a higher rate, as shown by the drastic loss of mass. This 9 transition is more clearly shown in Figure 13b. At 241 minutes a sudden increase of mass is 10 shown, corresponding to the manual extinction by the Fire Service. Previous increase of mass shown by scales $2 \mathrm{~A}, 3 \mathrm{~A}$ and $3 \mathrm{~B}$ correspond to falling debris that was not possible to correct.
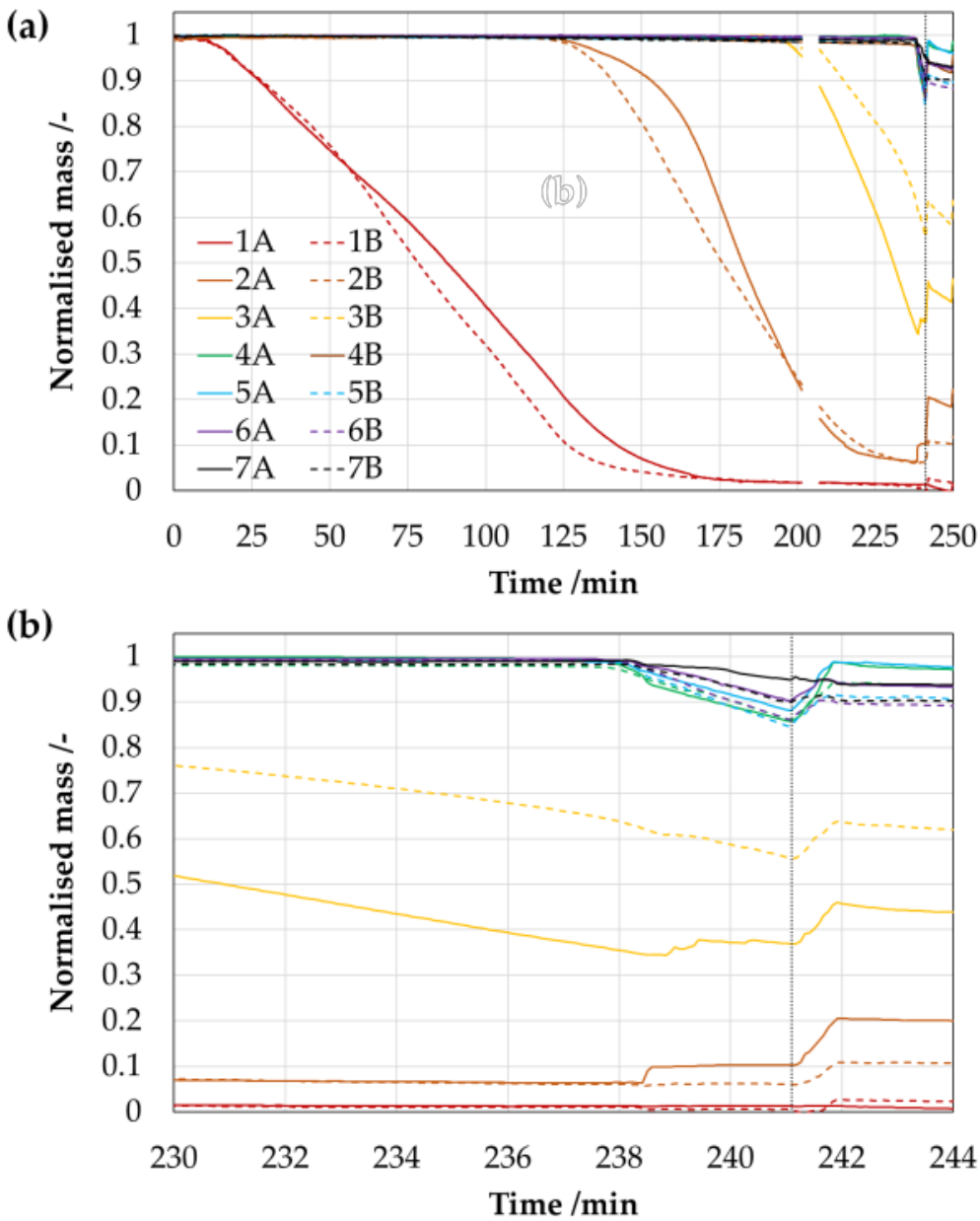

Figure 13. Normalised mass for each platform for (a) the whole duration of the test and (b) for a zoom in at 230-244 minutes. Extinction is shown as a vertical dotted line.

In order to establish a clear burning rate of the overall wood crib fuel in the compartment, Figure 14 shows the total mass loss rate from the wood cribs. Figure 14a shows the five clear domains with significantly different burning rates. These domains are denoted visually with 
1 the burning rate, which theoretically correlates to the increase of burning surface area as 2 shown in Figure 12. Note that the odd choice of units, g. $\mathrm{s}^{-1} / \mathrm{min}$, is justified to provide a better 3 interpretation of the variation in burning rate (normally expressed in $\mathrm{g} \cdot \mathrm{s}^{-1}$ ) for a long duration 4 test (easily expressed in minutes).

5 - Domain I (0 - 19 min): an initial peak up to 4 minutes, related to the kerosene-diesel

It is shown that the variation in burning rate observed for domains II to IV are consistent with those variations in observed fire length and size presented in Figure 12b. Therefore, it can be confirmed that the differences between domains are associated to an acceleration of the fire front.

24 The fluctuations in fire length and size observed for domain III (Figure 12b) are also observed in the burning rate (Figure 14); even more dramatically. Since these fluctuations occur when only one scale is affected, it is believed that this may not be caused by the transition between scales. Instead, it is believed that this could be caused by areas of the crib with increased 


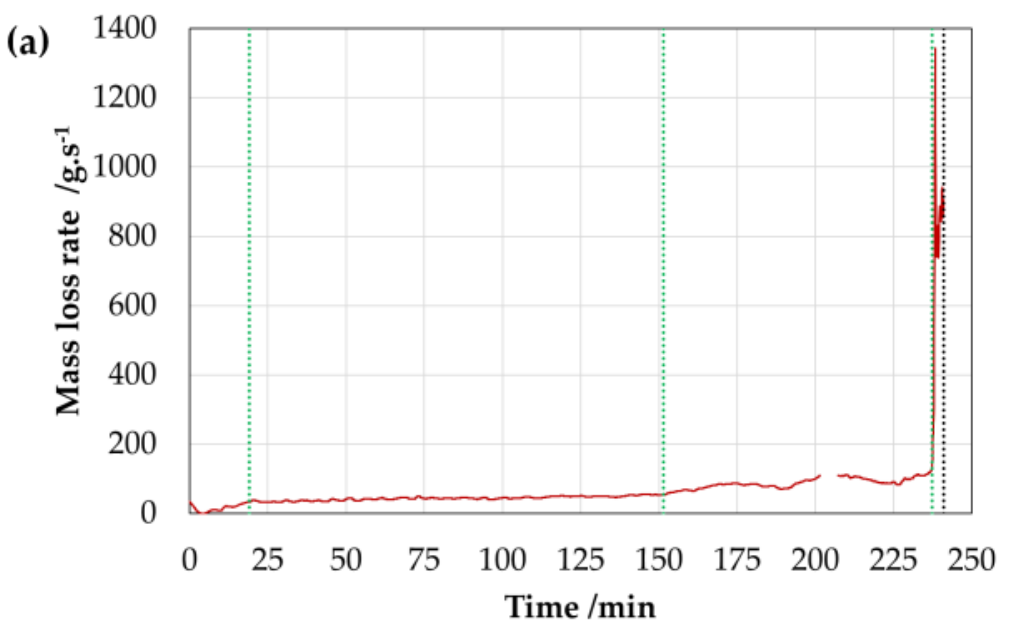

(b)
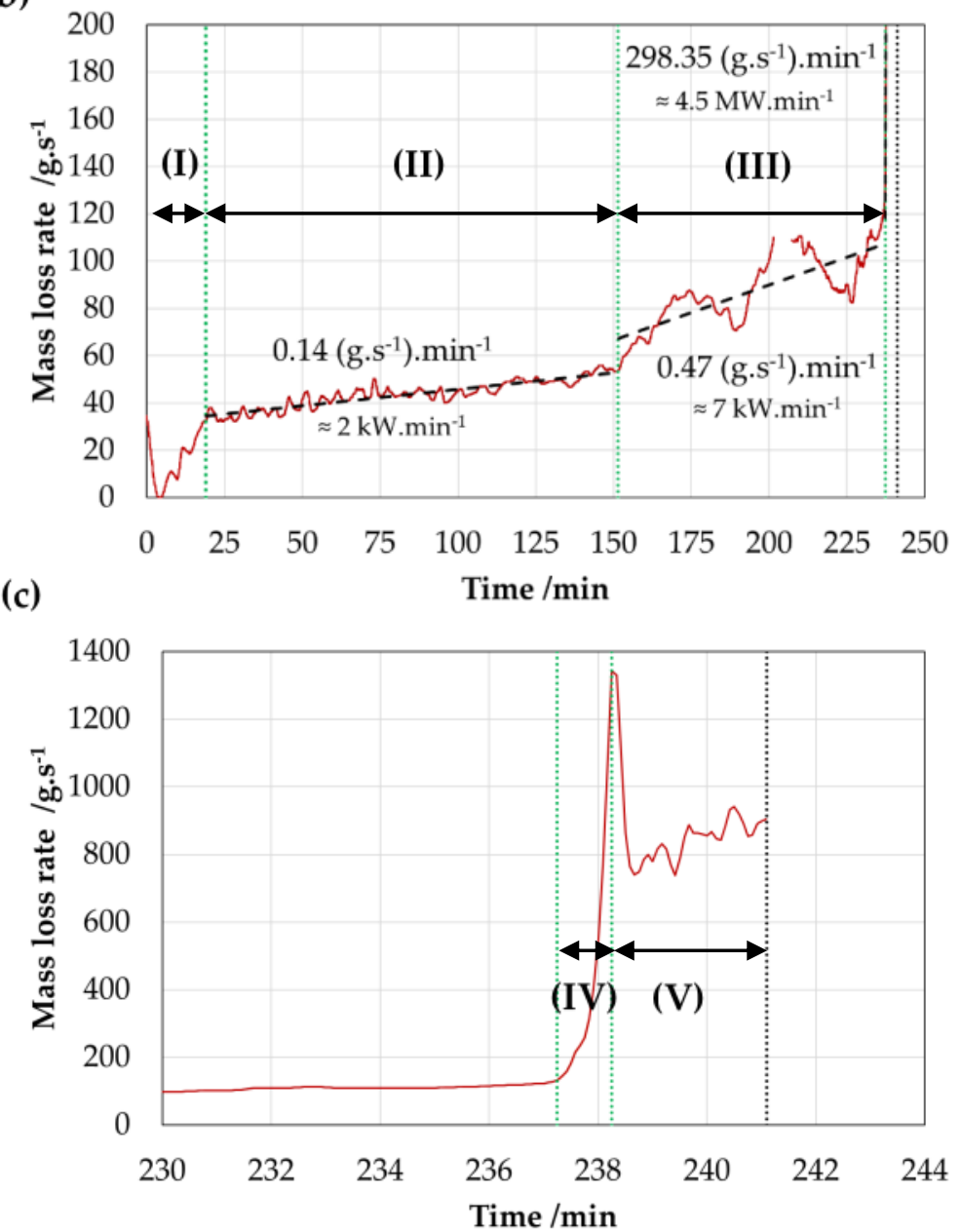

2 Figure 14. Total mass loss rate from the wood crib measured with the scales. Data has 3 been corrected taking into account debris that fell on the platforms and applying a locally 4 weighted scatterplot smoothing (LOESS) filter [34] for different domains independently.

5 (a) Complete duration of the test. (b) Zoom-in for a maximum MLR of 200 g.s $^{-1}$. (c) Zoom6 in for 230-244 minutes. Green vertical dotted lines indicate transitions between domains 7 observed in MLR. Black vertical dotted line indicates the manual extinction by the fire service. 


\subsection{Gas-phase temperature}

2 The evolution in the gas-phase temperature within the compartment is shown using contour plots based on the data from thermocouple trees. Figure 15 to Figure 18 show the representative thermal evolution for each of the domains observed in the previous section. These contour plots correspond to the centre-line thermocouple trees along the length of the compartment. Linear interpolation is used to represent the temperature in areas between thermocouple trees. White areas are regions where temperature data were not collected. The beam located in between areas of the compartment with and without cork attached to the ceiling is shown as an L-black shape. The cork is shown as a thin brown layer, whereas the thermocouples are represented as green dots. To better describe these plots, each of the domains from II to $\mathrm{V}$ are described independently:

- Domain II (Figure 15, 19 to $152 \mathrm{~min}$ ): characteristic temperature fields in the near field and the far field are clearly identifiable. Plots at 19 and 152 min suggest that the fire appears to be travelling, i.e. spreading via Mode $3\left(V_{S} / V_{B O} \approx 1\right)$, since a distinctive plume temperature field is observed. This is consistent with the slowly growing burning rate of the crib, which grows at a rate of 0.14 g.s $\mathrm{s}^{-1} \cdot \mathrm{min}^{-1}$. It is observed a slow but consistent increase in the overall gas-phase temperature, both in magnitude and volume of hot areas. Maximum gas-phase temperatures in the ceiling above the nearfield are below $300^{\circ} \mathrm{C}$.
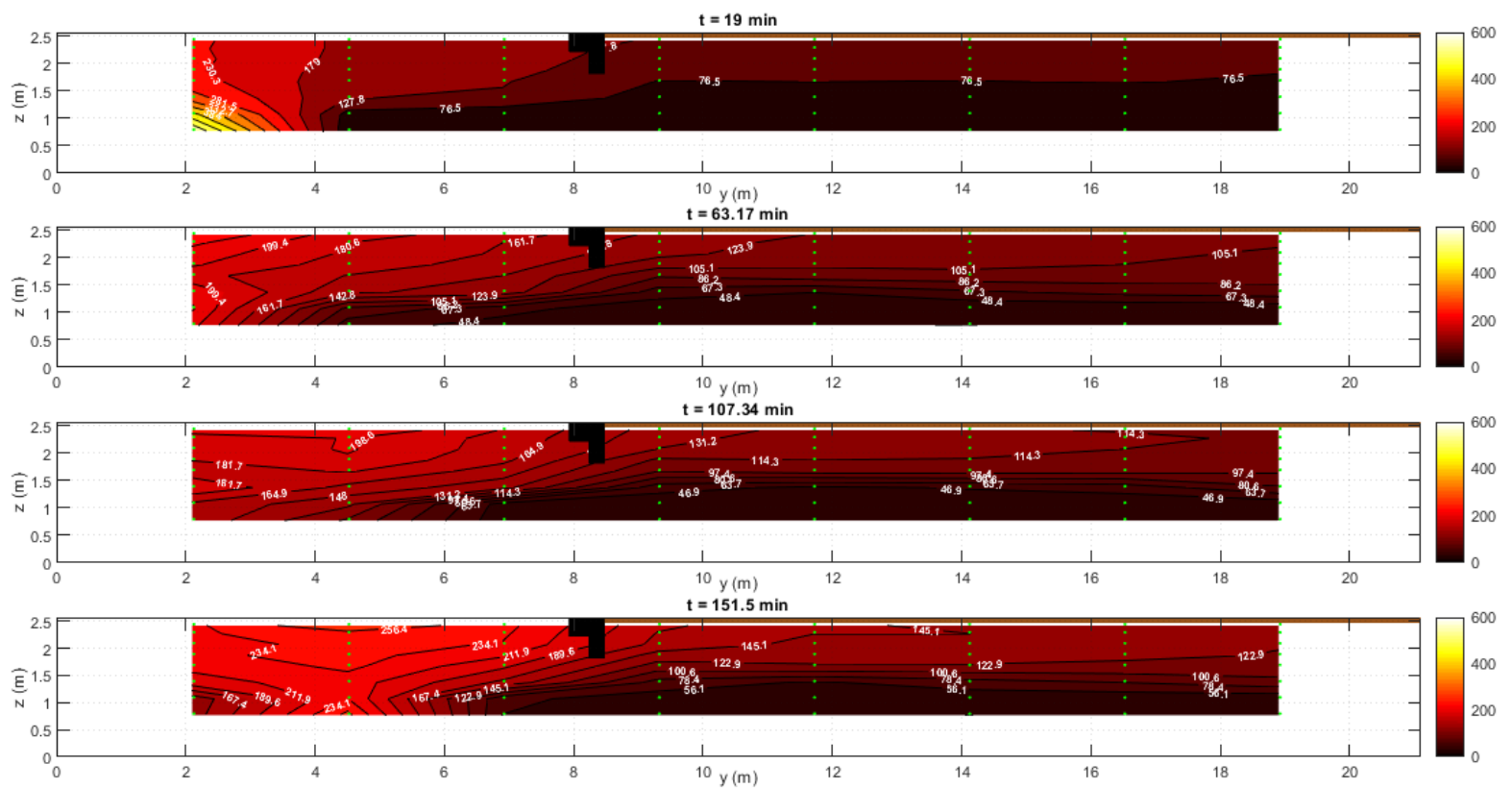

Figure 15. Gas-phase temperature contour along the centre-line of the compartment from 19 to 152 min (domain II).

- Domain III (Figure 16, 152 to $237 \mathrm{~min}$ ): between 160 and $234 \mathrm{~min}$, the fire appears to be travelling as per Domain II, however, the temperatures are increasing. This is consistent with the increase in burning rate, which grows at a rate of $0.47 \mathrm{~g} . \mathrm{s}^{-1} \cdot \mathrm{min}^{-1}$, and increase in fire size, which grows at a rate of $28 \mathrm{~mm} \cdot \mathrm{min}^{-1}$ (or $0.067 \mathrm{~m}^{2} \cdot \mathrm{min}^{-1}$ ) as described in the previous sections. This confirms that the fire is not only travelling but growing in size (surface area) as the burning rate increases - transition from Mode 3 
$\left(V_{S} / V_{B O} \approx 1\right)$ to Mode $2\left(V_{S} / V_{B O}>1\right)$. This behaviour is verified by the increasing area of the near-field temperatures which are characterised by higher temperatures. Additionally, it is observed that the beam disrupts the ceiling jet, as the temperature distribution observed on the far left-hand side of the compartment are higher than those observed beyond the beam on the right-hand side of the compartment. This behaviour changes from $234 \mathrm{~min}$, when a localised area of the cork ceiling on the right of the beam is increasing in temperature, with temperatures above the maximum temperature below the ceiling on the left of the beam. This is due to local ignition of the ceiling material in that location, which was verified visually. The flame on the ceiling appears to spread as the regions with higher temperature spread towards the right-hand side of the compartment. During this process, the flame is not rapidly spreading over the crib since the temperatures on the bottom thermocouples are significantly lower. At $237 \mathrm{~min}$, the fire on the crib reaches the thermocouple tree located on the right-hand side of the beam (close to $y=9 \mathrm{~m}$ ). 

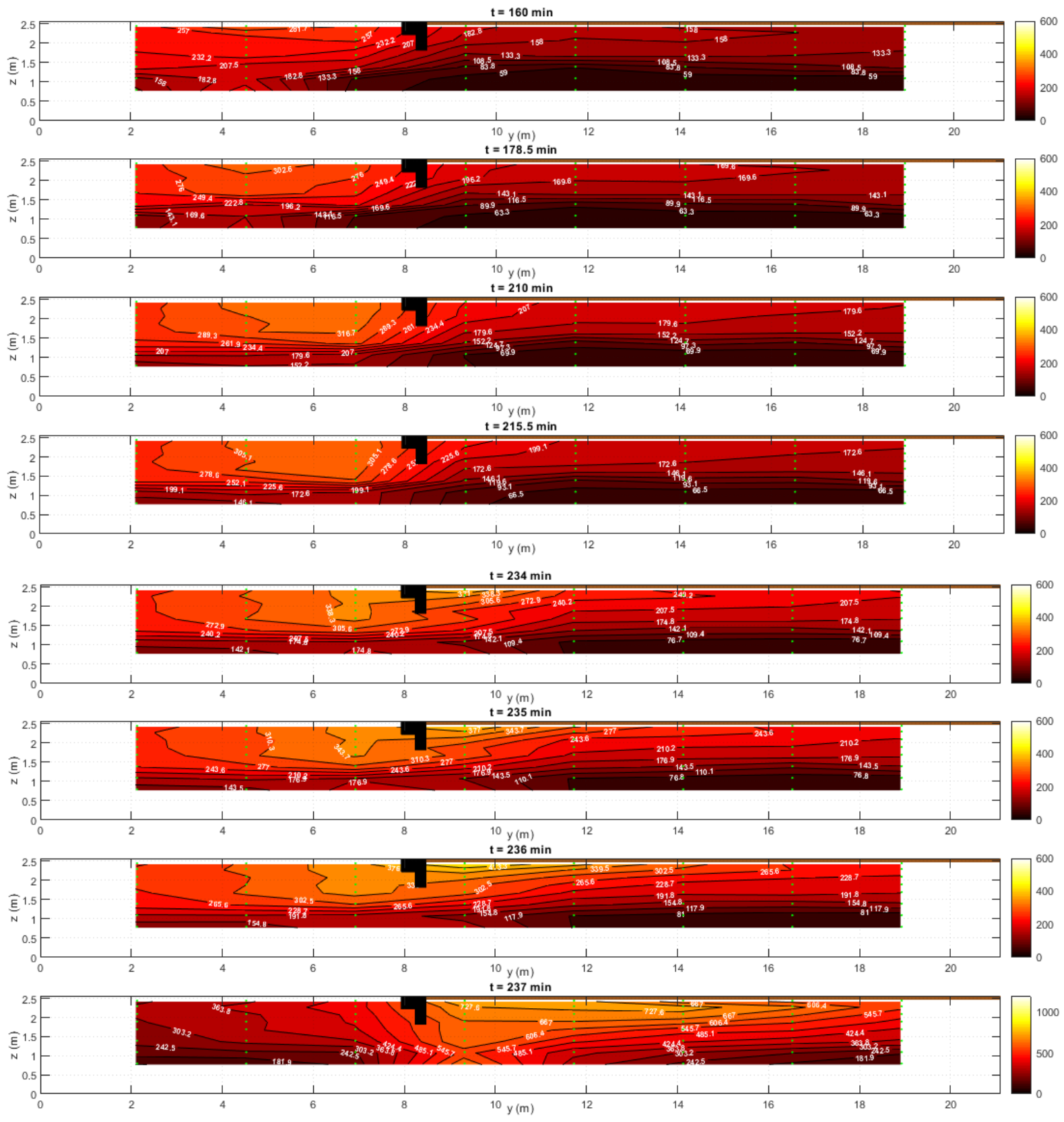

Figure 16. Gas-phase temperature contour along the centreline of the compartment from

152 to 237 min (domain III).

- Domain IV (Figure 17, 237 to $238 \mathrm{~min}$ ): following the ignition and flame spread of the cork insulation attached to the ceiling, after 237 minutes the fire transitions from Mode $2\left(V_{S} / V_{B O}>1\right)$ to Mode $1\left(V_{S} / V_{B O} \rightarrow \infty\right)$, accelerating rapidly over the surface of the wood crib. This is consistent with the large increase in burning rate presented in previous section, transitioning from a rate of $0.47 \mathrm{~g} . \mathrm{s}^{-1} \cdot \mathrm{min}^{-1}$ to $298.35 \mathrm{~g} . \mathrm{s}^{-1} \cdot \mathrm{min}^{-1}$. 

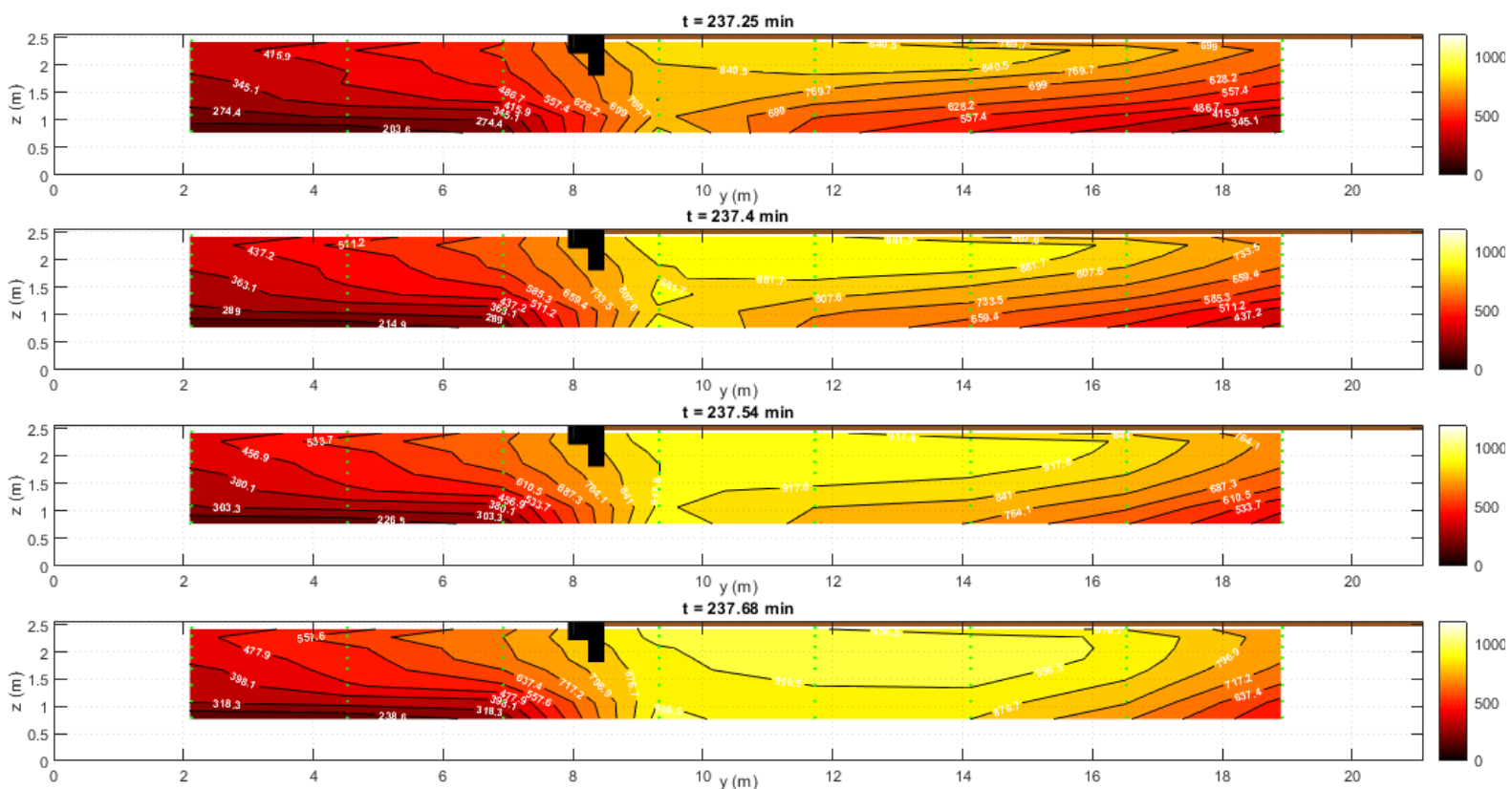

Figure 17. Gas-phase temperature contour along the centreline of the compartment from 237 to 238 min (domain IV).

- Domain V (Figure 18, $238 \mathrm{~min}$ to $240 \mathrm{~min}$ ): once the flame of the wood crib has spread up to the right end of the compartment, temperatures on the right-hand side of the compartment are approaching $800-1,000^{\circ} \mathrm{C}$, typical of fully-developed fires. The temperatures are more uniform at the centre of the crib $(y=[9 \mathrm{~m}, 17 \mathrm{~m}])$, with lower temperatures on at the edges $(\mathrm{y}<9 \mathrm{~m}$ and $\mathrm{y}>17 \mathrm{~m})$, presumably due to air entrainment and the absence of fuel on those areas. On the left-hand side of the compartment, there is a clearly defined two-zone behaviour. Nonetheless, a ceiling jet temperature pattern is observed in the hot layer, with increasing temperatures close to the area where all fuel burning $(\mathrm{y}>9 \mathrm{~m})$.
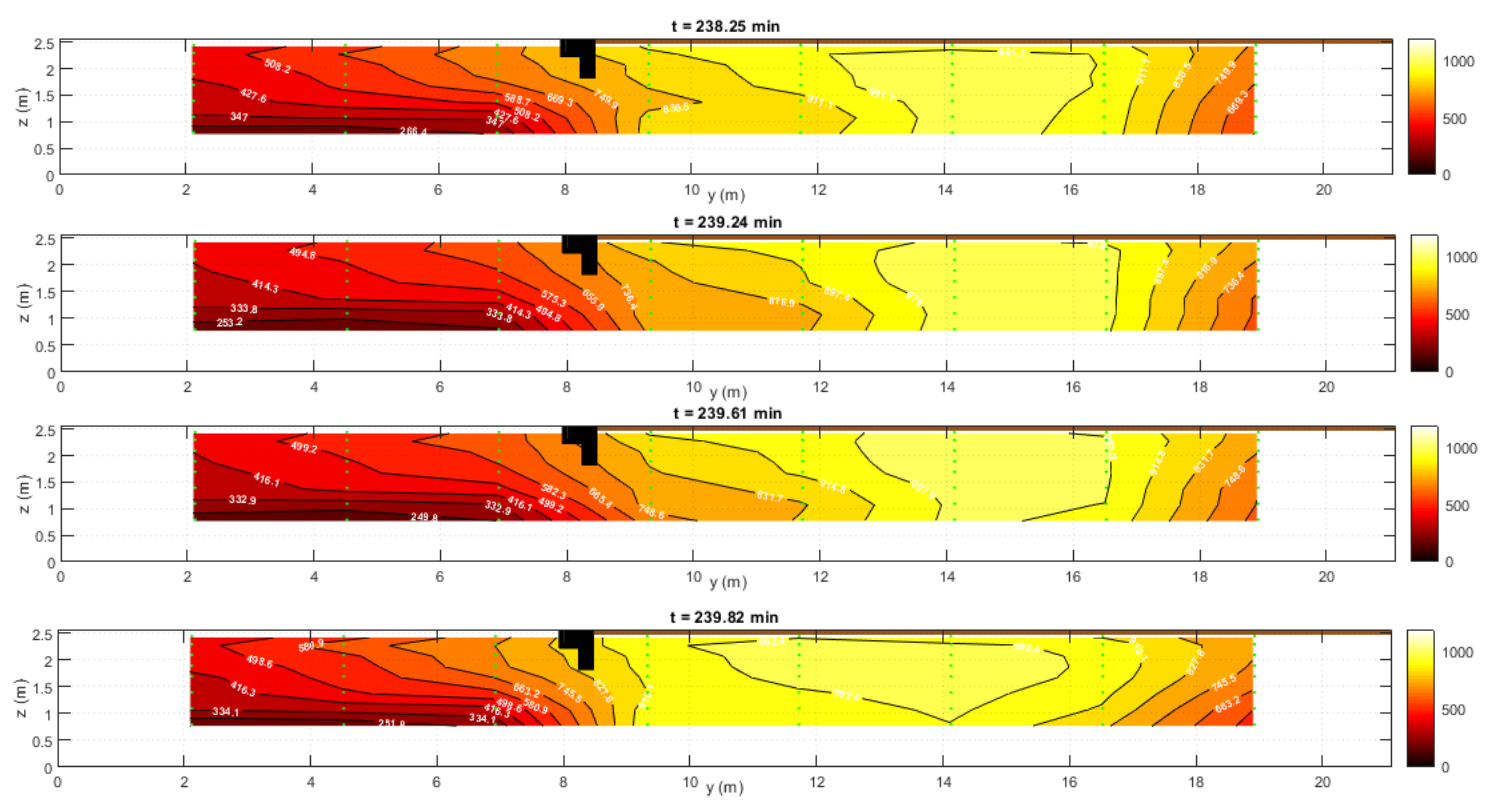

Figure 18. Gas-phase temperature contour along the centreline of the compartment from 238 to 240 min (domain V). 


\subsection{Incident radiant heat fluxes onto floor}

The evolution of the incident radiant heat flux onto the floor are shown in Figure 19. The two rows of TSCs correspond to Row 'Z0-A' and 'Z0-B' which are the rows of sensors along the $850 \mathrm{~mm}$ and $3850 \mathrm{~mm}$ planes in the x-axis, respectively. For the heat flux calculation using TSCs, it was assumed that the gas-phase at the floor level remained at ambient temperature, since thermocouples were not at the ground level and these would include radiation errors. The plots have been divided into the five domains.

- Domain I (0 to $19 \mathrm{~min}$ ). It can be seen that the measurements by most sensors are less than $1 \mathrm{~kW} \cdot \mathrm{m}^{-2}$ with the exception of HF-Z0-A1 and HF-Z0-B1, the TSCs located at $\mathrm{x}=$ $2200 \mathrm{~mm}$, and correspond to the sensors closest to the flames at this time. The heat flux of HF-Z0-A1 and HF-Z0-A1 increase from $0 \mathrm{kWm}^{-2}$ to roughly $5 \mathrm{kWm}^{-2}$ and $3 \mathrm{kWm}^{-2}$, respectively. The heat flux recorded by HF-Z0-A1 is higher than HF-Z0-B1, suggesting that the fire front position is not uniform in width or extra radiative feedback is received near the wall.

- Domain II (19 to $152 \mathrm{~min})$. HF-Z0-A1 and HF-Z0-B1 experience a decrease at approximately 20.7 minutes, which corresponds to the time at which the liquid ignition source consisting of the mixture of $5 \mathrm{~L}$ of kerosene and $0.5 \mathrm{~L}$ burning out, as confirmed visually by the video footage, whereby the production of smoke reduces as the liquid fuel is consumed. All other sensors indicate an increase in heat flux throughout the duration of this Domain. HF-Z0-A2 shows the highest increase from roughly $1 \mathrm{kWm}^{-2}$ to $6 \mathrm{kWm}^{-2}$. This change is not reflected by HF-Z0-B2, and this sensor reads consistently low values throughout the duration of the test indicating sensor failure. HF-Z0-A3 and HF-Z0-B3 read the third highest values throughout this Domain increasing to roughly $2 \mathrm{kWm}^{-2}$. These readings correspond to the fire location, which is between $\mathrm{y}=2200$ and $\mathrm{y}=5200$ during this domain, meaning the fire is over these sensors at this stage of the test.

- Domain III (152 to $237 \mathrm{~min}$ ). The period between 192 and 209 minutes is represented by a straight line as this corresponds to the period where the data logger failed and was rebooting, and thus no data was collected. HF-Z0-A2 remains the highest heat flux between 152 and 192.3 minutes as during this stage the fire is still closest to this sensor, as the flame front travels from approximately $y=5200$ to $y=7000 \mathrm{~mm}$ and the burnout front travels from $y=1650$ to $y=2410 \mathrm{~mm}$, and the values remain consistent for the entirety of the Domain. During the period where data was not collected, HF-Z0-A3 and HF-Z0-B3 begin to read the highest heat fluxes up until 236.9 minutes. The peak heat flux recorded during this stage by HF-Z0-A3 and HF-ZO-B3 are 15 and $10 \mathrm{kWm}^{-2}$ respectively. HF-Z0-A4 and HF-Z0-B4 begin to rise rapidly in their heat flux readings at around 220 minutes as the fire reaches the soffit, as confirmed by video footage. HFZ0-A5 and HF-Z0-B5 show a similar trend, however to a less extent being located further downstream of the fire. Between 221 and 226 minutes the data recorded by HFZ0-A3 was removed due to artificial noise from the TSC.

- Domain IV and Domain V (237 to $240 \mathrm{~min})$. Once the fire rapidly and almost instantaneously spread throughout the right side of the compartment at 
approximately 238 minutes, all TSCs failed, as indicated by a drop-in heat flux. Therefore, to reduce artificial data, all data following a decrease in heat flux beyond 238 minutes was removed.
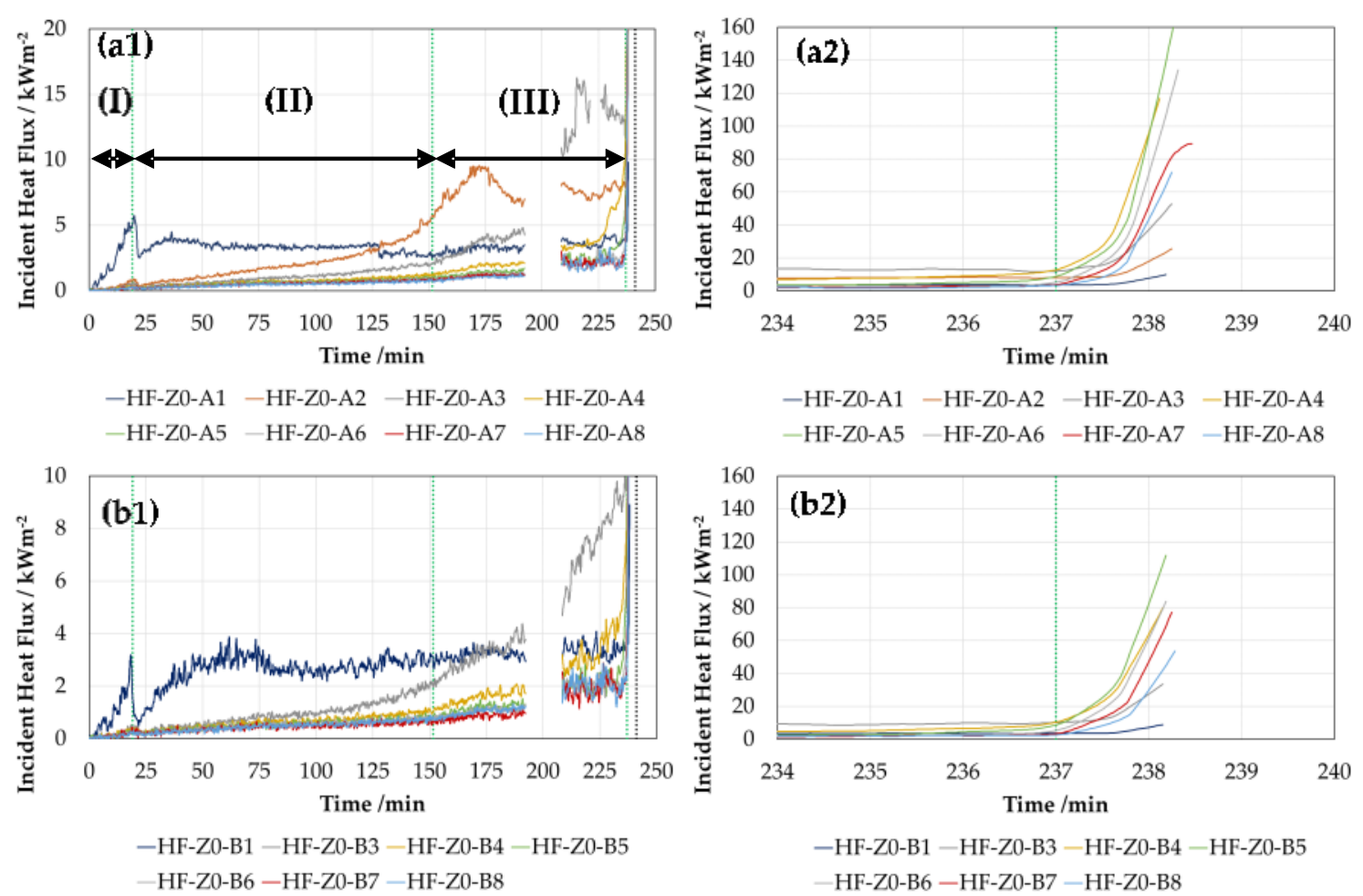

Figure 19. Incident radiant heat flux imposed on the floor along the length of the compartment at $x=850 \mathrm{~mm}$ ( $\mathrm{a}$ - next to back wall) and $x=3850 \mathrm{~mm}$ ( $b-$ next to window). (a2) and (b2) show a zoom-in for 234 to $240 \mathrm{~min}$, transition from domain IV to V.

Sensors 4 through 6 for both Rows A and B read the highest heat fluxes at this stage, as they are located to the right of the soffit where the fire first rapidly increases in size as it spreads throughout the right side of the enclosure. The peak heat fluxes recorded by each sensor during this Domain are provided in the table below, with the exception of TSC rows 1 and 2 as their peaks were recorded in Domains I and II.

Table 4. Peak heat fluxes recorded by the TSCs during Domains IV and V of the test. Maximum readings are constrained by premature failure of the instrumentation.

\begin{tabular}{|c|c|c|}
\hline y-position & $\begin{array}{r}\text { Row HF-Z0-A - } x=850 \text { mm (kW.m- } \\
2 \text { (2) }\end{array}$ & Row HF-Z0-B - $x=3850 \mathrm{~mm}\left(\mathrm{~kW} \cdot \mathrm{m}^{-2}\right)$ \\
\hline 3 & 49 & 33 \\
\hline 4 & 117 & 80 \\
\hline 5 & 139 & 112 \\
\hline 6 & 107 & 84 \\
\hline 7 & 75 & 69 \\
\hline 8 & 64 & 45 \\
\hline
\end{tabular}

15 The values recorded by Row B are generally lower, indicating that the flame front position was not constant with depth, and Row B was possibly impacted on by its location being adjacent to the openings. 


\subsection{Opening Flow Velocities}

2 The evolution of the gas in- and out-flow velocities are shown for each window. The 3 associated thermocouple trees are used in conjunction with the bi-directional probes to 4 calculate the respective density of air. Figure 20 shows the flow velocity of each bi-directional 5 probe located within a vertical array, with a negative flow velocity reading indicating an in6 flow, and positive flow velocity indicating an outflow. The transition between the in-flow to 7 out-flow is described as the neutral pressure plane region. Like Section 5.3, each of the plots 8 describe each domain independently.
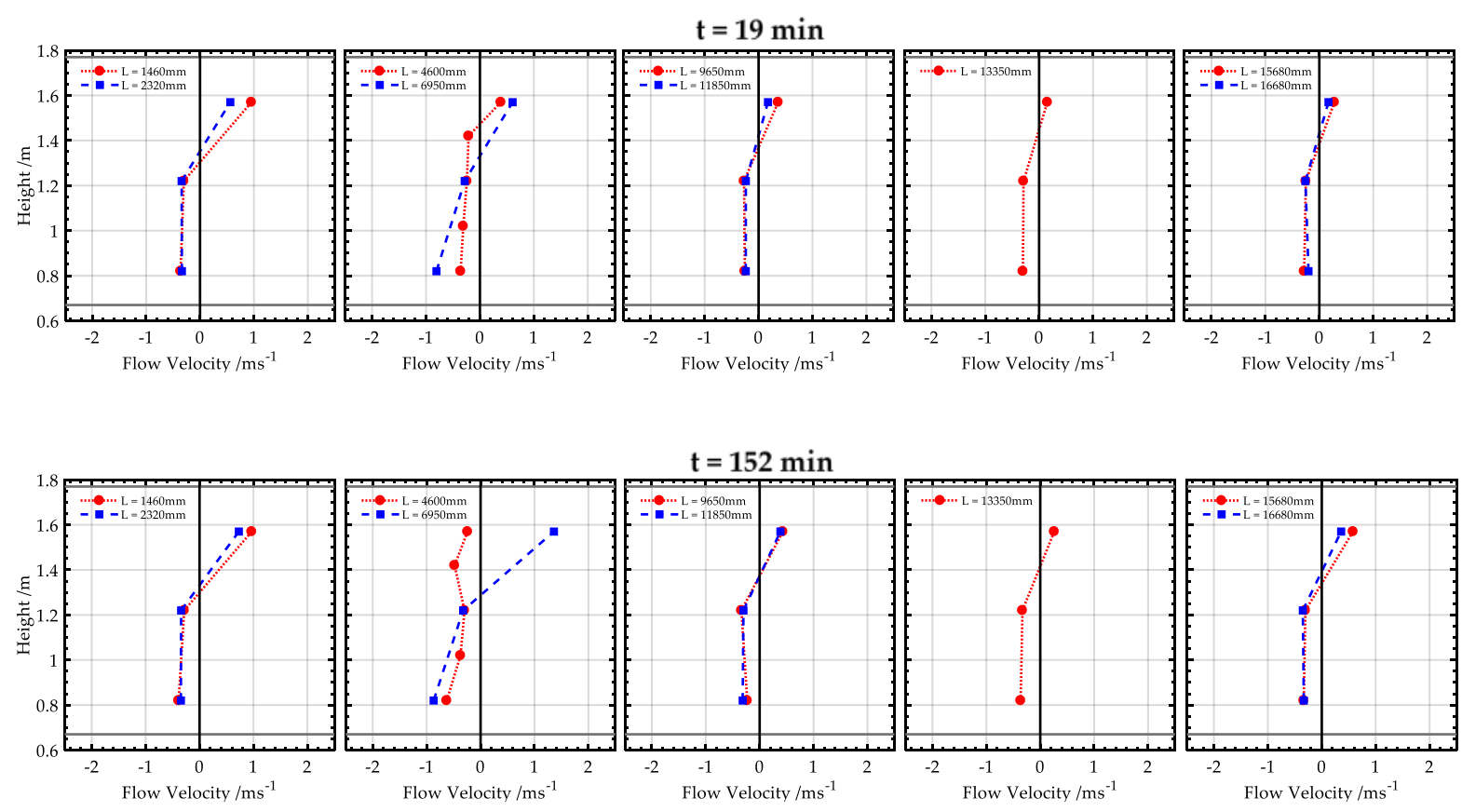

Figure 20. Flow velocities at each of the five window openings during the time of domain II (19 $\mathrm{min}$ to $152 \mathrm{~min}$ ). Each plot represents in ascending order, each opening along the length of the compartment (i.e. the plot on the left corresponds to W1 and the plot on the right corresponds to W5).

- Domain II (Figure 15, 19 to $152 \mathrm{~min}$ ): at $19 \mathrm{~min}$, characteristic velocities through opening 1 and opening 2 are higher than the other openings, indicating that the plume from the fire is starting to develop and hot convective flows are leaving locally through the openings close to the fire. Opening 3 onwards shows constant inflow velocities for each height, up until the neutral plane region, $H_{N}$, which is defined as the transition region from inflow to outflow velocities and lies in-between $1.42 \mathrm{~m}$ and $1.57 \mathrm{~m}$ above the false floor level. The plots at $152 \mathrm{~min}$ show that at $\mathrm{y}=4.6 \mathrm{~m}$, the velocities recorded are all negative (i.e. flowing into the compartment). This could be induced by local entrainment of air from the near-field of the fuel-controlled travelling fire, which is indicative of the region for which the flame front is located. The peak velocity is recorded at $1.4 \mathrm{~m} / \mathrm{s}$, which is the probe array located just downstream of the flame front $(y=6.95 \mathrm{~m})$. 

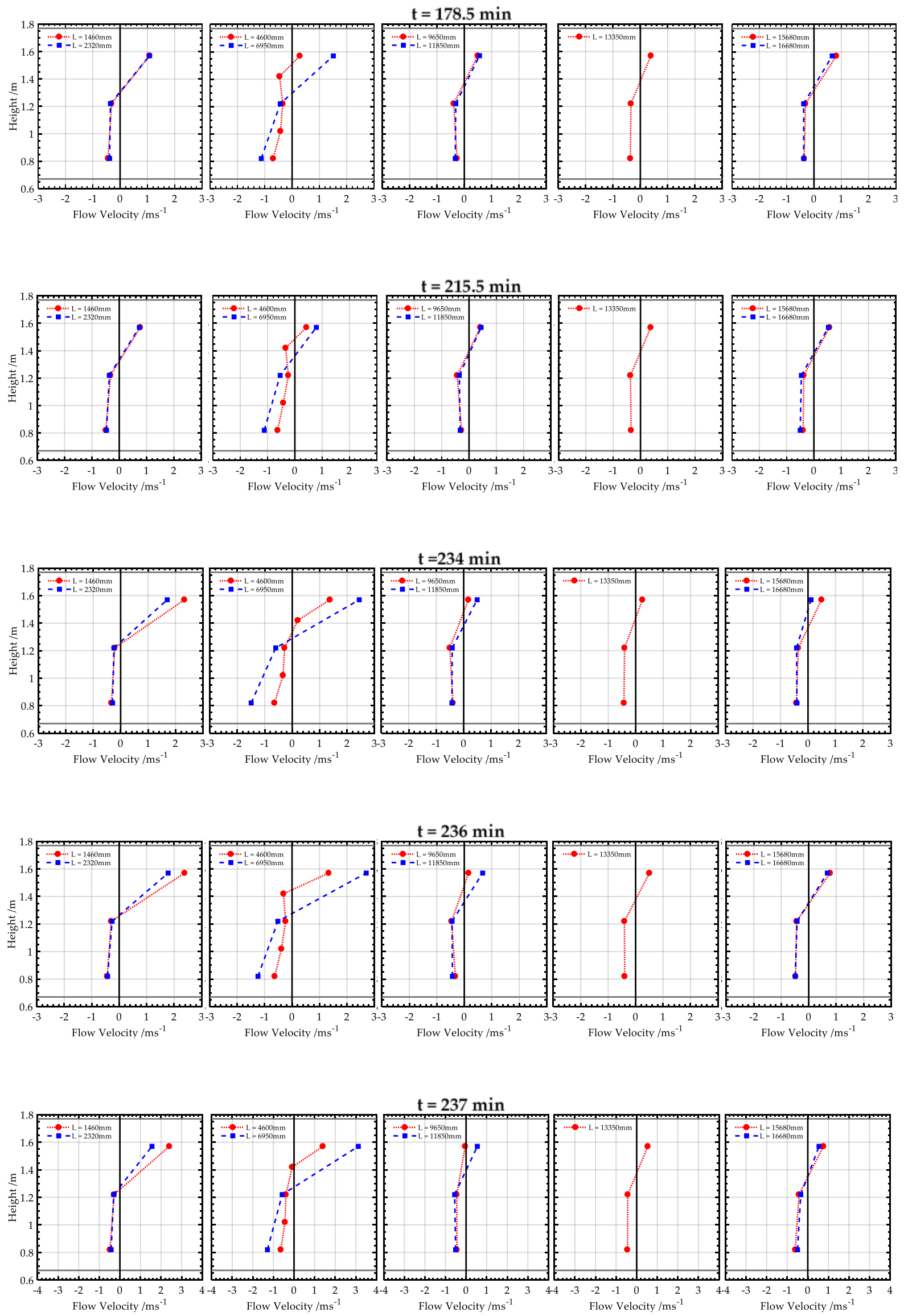
1 Figure 21. Flow velocities at each of the five window openings during the time of domain 2 II (152 $\mathrm{min}$ to $237 \mathrm{~min}$ ). Each plot represents in ascending order, each opening along the 3 length of the compartment.

- Domain III (Figure 21, 152 to $237 \mathrm{~min}$ ): between 160 and $215.5 \mathrm{~min}$, the fire front (as defined from the mass loss rate recorded using the scales) is located in-between the two probe arrays in opening 2 . This is observed with the low flow readings at $\mathrm{L}=$ $4600 \mathrm{~mm}$ at $160 \mathrm{~min}$, and then at $\mathrm{L}=6950 \mathrm{~mm}$ at $215.5 \mathrm{~min}$, indicating a local entrainment effect dominating the flow field at the opening of this point. Within this period, the highest flows are recorded at the probes just downstream or upstream of the fire front, followed by opening 1. Between $215.5 \mathrm{~min}$ and $237 \mathrm{~min}$, the fire front has transitioned to the region in-between opening 2 and opening 3, with the upstream velocities in opening 1 and opening 2 increasing substantially. At $234 \mathrm{~min}$, the neutral plane height has descended at opening 2, such that the neutral plane region lies inbetween $1.22 \mathrm{~m}$ and $1.42 \mathrm{~m}$, corresponding with visually observed descending smoke layer triggered by the ignition of the cork ceiling. Peak outflow velocities are recorded in-between $2.5 \mathrm{~m} . \mathrm{s}^{-1}$ and $2.7 \mathrm{~m} . \mathrm{s}^{-1}$ at $\mathrm{L}=6950 \mathrm{~mm}$, which is the probe upstream of the rapidly expanded fire front, followed by the probes located in opening 1 , which range from $1.6 \mathrm{~m} . \mathrm{s}^{-1}$ to $2.3 \mathrm{~m} . \mathrm{s}^{-1}$. Near-wall velocities recorded by the probe array at $\mathrm{L}=1460$ $\mathrm{mm}$ consistently records the second highest outflow velocities. It is important to note that inflow velocities through Domain III are shown to be constant, with probes located downstream of the fire, also recording consistent values.

The probe data for domain IV and domain V are not presented herein, as the probes located downstream of the fire were engulfed in external flaming, with the plastic hoses connecting the probes and transducers starting to heat and possibly melting.

\subsection{Heat release rate quantification}

The heat release rate of the fire is estimated using a mass loss rate calorimetry approach, using the burning rate of the wood crib. A range of [12.8 - 20.4] MJ.kg-1 for the heat of combustion of two species of pine wood [Error! Reference source not found.] is assumed to consider the uncertainty in the material and efficiency of the combustion. The HRR is shown in Figure 22, and it can be identified that the transition to fully-developed fire (or flashover/thermal runaway) is shown approximately near 2.1MW. It should be noted that this HRR estimation does not consider the burning of the cork insulation, and therefore the true value would be expected to be higher from $237 \mathrm{~min}$, where the transition is identified. 

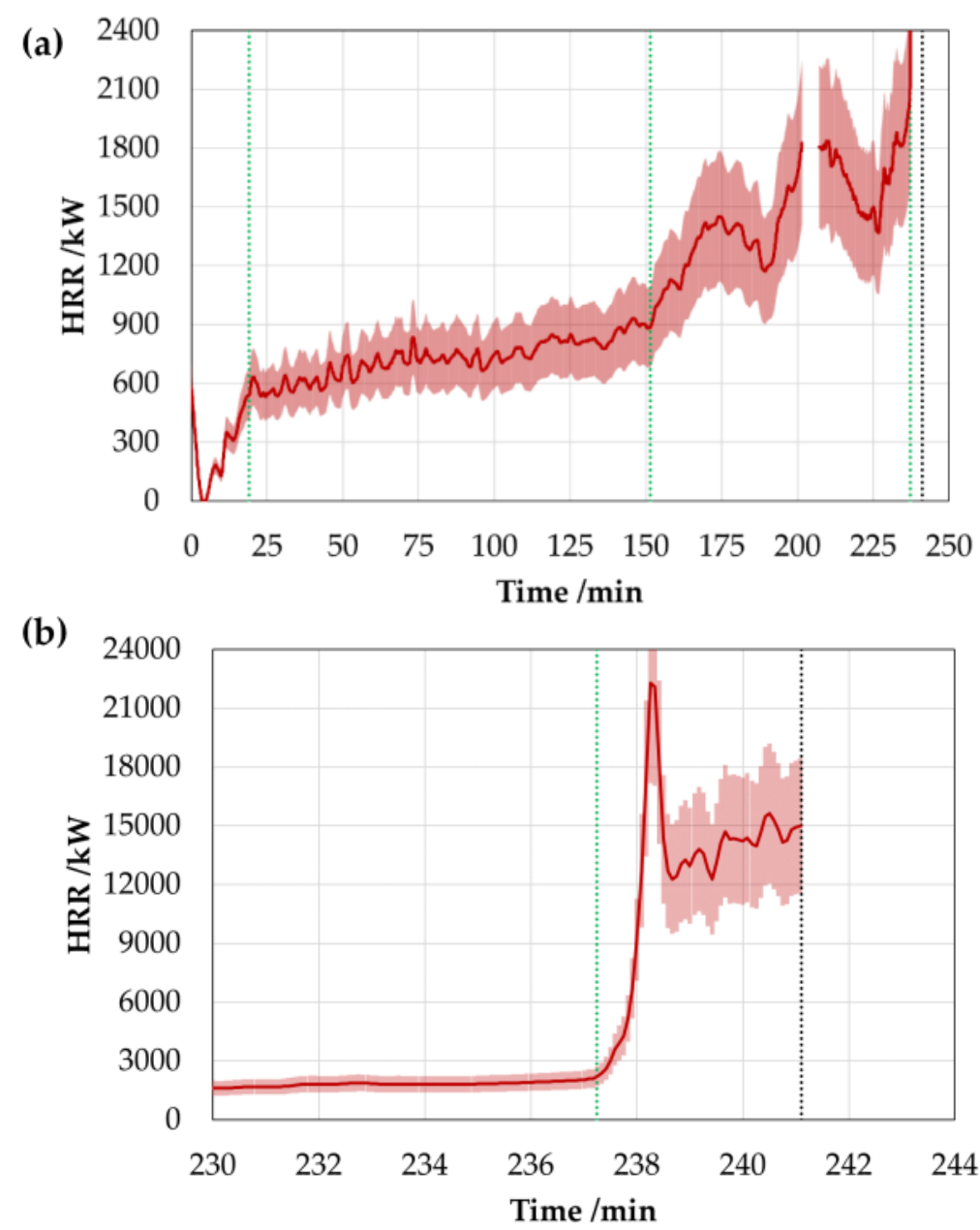

Figure 22. Estimation of HRR based on MLR from scales. Error bars provide maximum and minimum HRR using 12.8 and 20.4] MJ.kg-1 as the heat of combustion.

\section{Summary and discussion}

\section{$5 \quad 6.1$ Fire behaviour modes}

6 A preliminary analysis of the results presented in the previous section indicates that the compartment fire experienced the three distinct fire modes for the floor fuel load formerly

8 presented by Hidalgo et al. [22]. Applying a linear fit to the fire front and burnout front 9 position for each of the domains presented in Figure 12, an average velocity can be estimated 10 using the slope of the linear fit. Average velocities and the ratio between these are presented 11 in Table 5 below.

12 Table 5. Average fire front and burnout front velocity for each time domain using linear 13 fitting functions. Ratio between these velocities and fire behaviour mode are shown.

\begin{tabular}{|c|c|c|c|c|}
\hline $\begin{array}{l}\text { Time } \\
\text { domain }\end{array}$ & $\begin{array}{l}\text { Fire front velocity }\left(V_{s}\right) \\
\text { /mm.min-1 }\end{array}$ & $\begin{array}{l}\text { Burnout front velocity }\left(V_{B o}\right) \\
/ / \mathrm{mm} \mathrm{min}^{-1}\end{array}$ & $\begin{array}{c}V_{s} / V_{B O} \\
/-\end{array}$ & Fire mode \\
\hline I & 21 & 0 & $\rightarrow \infty$ & - \\
\hline II & 13 & 12 & 1 & $V_{s} / V_{B O} \approx 1$ \\
\hline III & 54 & 26 & 2 & $V_{s} / V_{B O}>1$ \\
\hline
\end{tabular}




\begin{tabular}{|c|c|c|c|c|}
\hline $\mathrm{IV}$ & 2977 & 26 & 116 & $\boldsymbol{V}_{\boldsymbol{s}} / \boldsymbol{V}_{\boldsymbol{B} \boldsymbol{O}} \rightarrow \infty$ \\
\hline $\mathrm{V}$ & - & - & - & $\boldsymbol{V}_{\boldsymbol{s}} / \boldsymbol{V}_{\boldsymbol{B} \boldsymbol{O}} \rightarrow \infty$ \\
\hline
\end{tabular}

Each of the fire modes identified were characterised by the following conditions. It should be noted that domain I is excluded from the three modes, since it corresponds to the early transient growth with the burnout front not developed yet.

- A travelling mode $\left(V_{S} / V_{B O} \approx 1\right)$ corresponding to domain II with a burning rate in the range 36 g.s $\mathrm{s}^{-1}-55 \mathrm{~g} . \mathrm{s}^{-1}$ that lasted $133 \mathrm{~min}$. The fire length had an average value of $1.2 \mathrm{~m}$ (corresponding to a fire size of $2.88 \mathrm{~m}^{2}$ ), which grew at an average rate of 2 $\mathrm{mm} \cdot \mathrm{min}^{-1}$. The incident radiant heat flux imposed on the fuel bed ahead of the fire front was below $6 \mathrm{~kW} \cdot \mathrm{m}^{-2}$.

- A growing mode $\left(V_{S} / V_{B O}>1\right)$ corresponding to domain III with a burning rate in the range 55 g.s $\mathrm{s}^{-1}-100 \mathrm{~g} . \mathrm{s}^{-1}$ that lasted $85 \mathrm{~min}$. The fire length had an average growth rate $28 \mathrm{~mm} \cdot \mathrm{min}^{-1}$ (corresponding to a size growth of $0.067 \mathrm{~m}^{2} \cdot \mathrm{min}^{-1}$ ). The average rate at which the burning rate grew was $0.47 \mathrm{~g} . \mathrm{s}^{-1} \cdot \mathrm{min}^{-1}$, caused by an increase in the burning area. The incident radiant heat flux onto the floor ahead of the fire front were below 10-15 kW.m-2.

- A mode with an extremely rapid or instantaneous spread of the fire front such that the fire immediately covers the entire available fuel surface in the compartment $\left(V_{S} / V_{B O} \rightarrow \infty\right)$, commonly defined as flashover transitioning to a fully-developed fire. This corresponds to domain IV with an extremely rapid fire growth $\left(1.686 \mathrm{~m} . \mathrm{min}^{-}\right.$ ${ }^{1}$ for the fire length and $298.35 \mathrm{~g} \cdot \mathrm{s}^{-1} \cdot \mathrm{min}^{-1}$ for the burning rate) that occurred within a minute and reached a peak burning rate of approximately $1.3 \mathrm{~kg} . \mathrm{s}^{-1}$. Subsequently, in domain $\mathrm{V}$, the fire covered the available fuel surface on the floor, for $2 \mathrm{~min}$ and an average burning rate in the range $800-900$ g.s $\mathrm{s}^{-1}$. This short duration was due to the intervention of the fire service for safety reasons. It should be noted that this stage would have been expected to continue until the consumption of the fuel load. Incident radiant heat fluxes onto the floor during domain IV were increasing above $15 \mathrm{~kW} \cdot \mathrm{m}^{-2}$ and reaching maximum values within the range 112 to $134 \mathrm{~kW} \cdot \mathrm{m}^{-2}$ during domain $\mathrm{V}$ until the sensors failed.

\subsection{Transition between fire modes}

Analysis of the conditions governing the transition between fire modes is of extreme importance towards establishing a comprehensive framework for compartment fires in openfloor plan spaces. This section presents a brief discussion of the conditions observed within each fire mode, and the transition between modes.

The initial mode, the travelling fire mode $\left(V_{S} / V_{B O} \approx 1\right)$, was characterised by being almost steady process with very slow increase in burning area and therefore burning rate. It can be assumed that the energy distribution in the compartment enabled a fire front spread velocity equivalent to the burnout front velocity (refer to Figure 12 and Table 5). It is theorised that the principal driver dictating the flame propagation is the local radiation from the flame itself, given that the heat fluxes from the smoke layer onto the floor were relatively low $\left(<6 \mathrm{~kW} . \mathrm{m}^{-}\right.$ 
$\left.\begin{array}{ll}1 & 2\end{array}\right)$, with a relatively thin smoke layer. At these heat fluxes, preheating of the crib by the smoke

2 will be very slow and thus not affect the flame spread or burning rates.

3 The transition of the fire from the travelling mode $\left(V_{S} / V_{B O} \approx 1\right)$ into the growing mode $4 \quad\left(V_{S} / V_{B O}>1\right)$, and subsequently to a fully-developed mode $\left(V_{S} / V_{B O} \rightarrow \infty\right)$ is justified by an 5 acceleration of the fire front over the burnout front, which is evidenced by the increasing 6 burning area and therefore burning rate. In this stage, the heat from the smoke layer appears 7 to affect more the fire front velocity, i.e. a flame spread surface phenomenon, than the burnout 8 front velocity, i.e. the burning rate phenomenon controlled by charring. The development of 9 an increasing heat flux ahead the fire front was observed, up to $10-15 \mathrm{~kW} \cdot \mathrm{m}^{-2}$ (refer to Figure 10 19) before the transition to a fully-developed fire.

11 Until detailed energy distribution analyses are performed, it can be assumed that the increase 12 of heat flux is due to a change in the energy balance in the compartment. The change in the energy balance may be induced by a reduction of heat losses through the boundaries, trapping or containment of heat in a localised area of the compartment by the physical geometry, and extra heat release contribution within the compartment - essentially all playing the same role. The results presented in previous sections show that both the $500 \mathrm{~mm}$ deep soffit beam located at $\mathrm{y}=9940 \mathrm{~mm}$ and the cork insulation have played a driving role in the transition of fire modes.

19 It is hypothesised that the transition of the fire from the travelling mode (domain II) to the growing mode (domain III) of the test might be triggered by the presence of the soffit beam. This is illustrated in the temperature contour plots shown in Figure 15 and Figure 16. While domain II displayed a thin smoke layer, as the fire approaches the beam it results in an obstruction that promotes smoke layer accumulation within the left side of the compartment which in turns provide a source of heat feedback into the fire and fuel allowing for the burning rate to increase. For domain II the fire plume temperatures in the nearfield were consistently lower than $200{ }^{\circ} \mathrm{C}$; these near-field temperatures increase to above $300{ }^{\circ} \mathrm{C}$ as the fire approaches the soffit. The analysed data supports the believe that the opening of the door did not play a major role. This may need to be verified using models to describe the velocity fields induced by the opening of the door.

It was observed that the transition of the fire from the growing mode (domain III) to the fullydeveloped mode is strongly related to the presence the cork on the ceiling. Due to its the low thermal inertia ( $<10^{4} \mathrm{~W}^{2} \mathrm{~s} \mathrm{~m}^{-4} \mathrm{~K}^{-2}$ [Error! Reference source not found.]), ignition and fire spread over the cork on the ceiling is very fast, thus the transition is abrupt. The cork insulation, although a charring material, can sustain burning if sufficient heat is provided leading to a significant change in the thermal balance in the compartment. Even though cork has been shown by several authors to provide a relatively low HRR $\left(120-206 \mathrm{~kW} \cdot \mathrm{m}^{-2}\right.$ as shown by [28]) it is clear that in this case the heat released by the cork has an impact sufficiently important to trigger the transition. Presumably, as the energy was released on the ceiling of the compartment heat losses and air entrainment are reduced, with both effects contributing

40 towards the transition. These two mechanisms of behaviour/contribution from the insulation 41 have previously been discussed by Hidalgo et al. [30]. 
1 The presence of soffit beam and the thermal insulation material, whereas very characteristic 2 of the scenario studied, evidences the importance of adequately defining the thermal energy

3 balance in the compartment so that realistic fire modes can be used as input design scenarios

4 in open-plan floor compartments.

5 Further investigation is required to provide a better understanding of the sensitivity of the 6 spread velocity of the fire front $\left(V_{S}\right)$ and the burnout front $\left(V_{B O}\right)$ to the external heat flux.

7 Consolidated research has demonstrated that the flame spread $\left(V_{S}\right)$ is primarily a function of 8 the fuel thermal inertia and the external heat flux whereas the burnout time is a function of 9 the fuel density and mass loss rate per unit area, which depends on the external heat flux [35].

\section{$10 \quad 6.3$ Identification of fire regime in domain $\mathbf{V}$}

11 The analysis of fire regime is only undertaken for the domain $\mathrm{V}$ of the fire, which corresponds 12 to a fully-developed fire. The temperatures observed in the right end of the compartment 13 following ignition of the cork ceiling and rapid flame spread across the right end of the 14 compartment have been compared to the theoretical temperatures in Regime I fires using the 15 Thomas plot [11]. The opening factor was then calculated by dividing the enclosure into two 16 compartments (refer to Table 2), as the fire was effectively only taking place in the right end 17 as all fuel on the left of the central beam had been consumed. The temperatures used to 18 compare the experimental results to the 'Compartment Fire Framework' were taken as the 19 average temperature within the right end of the compartment during the steady-state burning 20 of domain $\mathrm{V}$, which took place approximately between 239 and 241 minutes as shown in 21 Figure 23.

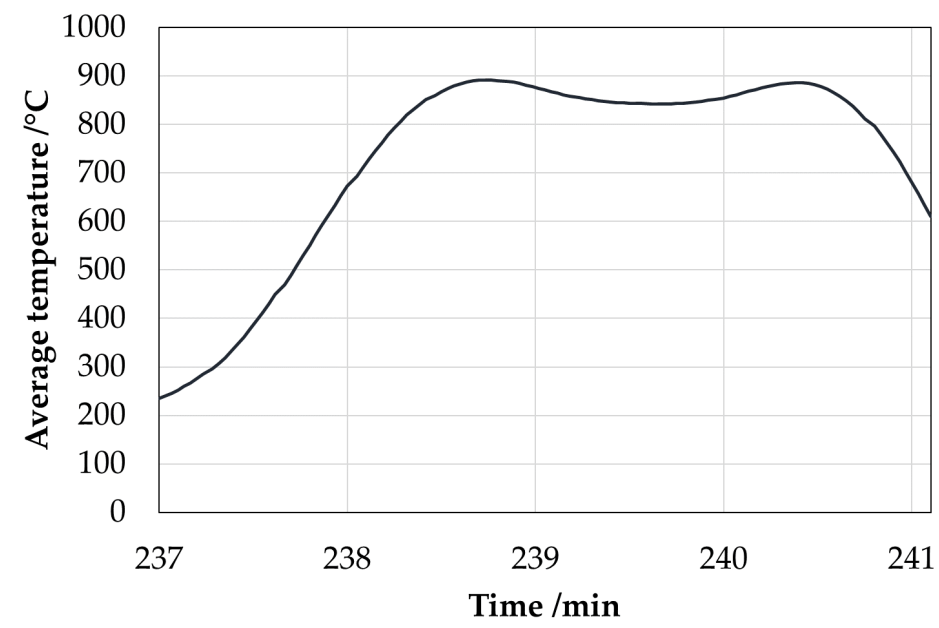

Figure 23. Average temperature within the compartment during domain V.

The average temperature was found to be $862 \pm 131^{\circ} \mathrm{C}$; this interval corresponds to the spatial variation in temperature. The peak temperature reading throughout the entire test was found to be $1056^{\circ} \mathrm{C}$. A comparison of these values to the Thomas plot is shown in Figure 24 . Note that the opening factor is computed by excluding the fuel and opening surfaces from $A_{T}$. The steady-state fire briefly observed during domain $\mathrm{V}$ is shown to be representative of a Regime II fully-developed fire, with the average fire temperature during this stage being very closely estimated by the data collected by Thomas and with significant spatial variability. The 
maximum temperature reading within the compartment is more indicative of a Regime I fire;

2 however, this was recorded by thermocouple A5-5 at 239 minutes with similar temperature

3 recorded in Row 5 of the thermocouple trees. It is assumed that this occurred as the flame

4 engulfed the sensors.

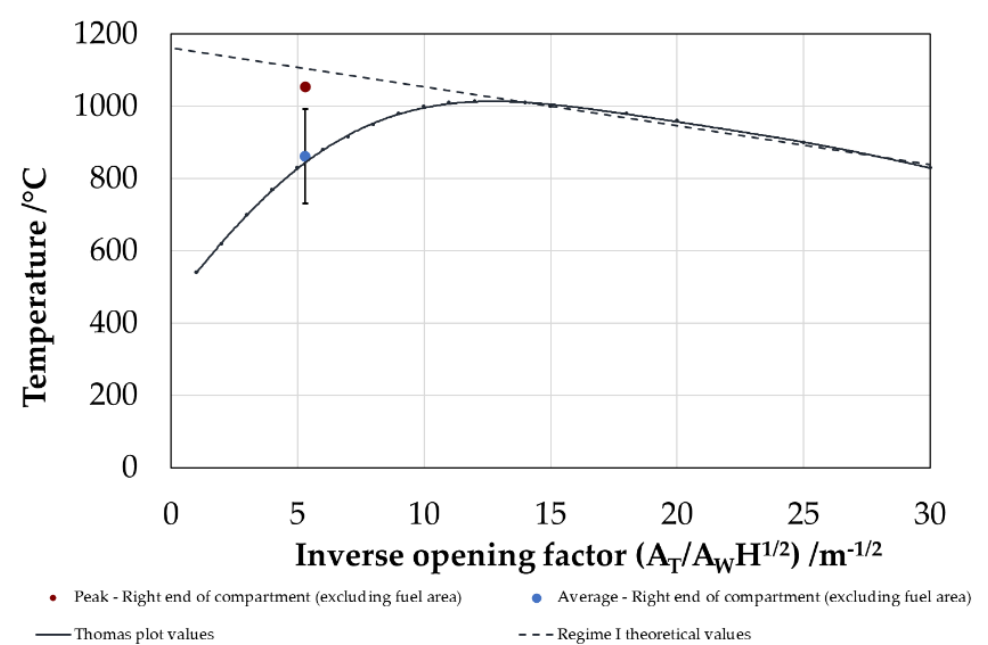

Figure 24. Comparison of experimental results of domain V (fully-developed fire) to the Thomas plot [11]. The blue point represents the average temperature within the compartment during this phase and red the maximum recorded temperature. The dashed line depicts the maximum temperature according to Regime I theory

\section{Conclusions}

This paper presents the characterisation of the Large-Scale Demonstrator 'Malveira Fire Test', which took place in a well-ventilated, open-plan compartment in Povoa de Galera, Malveira, Portugal in 2014. The principal source of fuel was a continuous bed of wood cribs running the length of the compartment, parallel to the ventilation, closely replicating the setup of the Edinburgh Tall Building Tests. The high density of instrumentation enabled significant spatial resolution of the thermal conditions and thus enabled a quantitative interpretation of the visual observations.

Three fire behaviour modes are clearly identified based on the experimental data, corresponding to a travelling fire, a growing fire, and a fully-developed fire; appearing sequentially as the fire moves along the entire length of the compartment. These modes are defined by the ratio between the flame front velocity and burnout front velocity. The transition between fire modes, and thus evolution of energy production appears strongly linked to the spatial redistribution of energy produced, and specifically to the evolution in heat feedback to the unburned fuel. This energy redistribution is strongly coupled with the variation in physical characteristics of the compartment along its length, e.g. openings, thermal characteristics of the boundaries, compartment geometry, etc.

This test illustrates the importance of, and thus need for, accurate characterisation of the dominating mechanisms driving the flows within the compartment at each stage of the fire 
development. The above governs the energy redistribution during the fire and therefore the ability of the fire to transition from one fire mode to another. Accurate characterisation of the expected fire dynamics during each expected mode will in turn enable the adequate design of the fundamental elements (pressurisation systems, structural fire protection, etc.) underpinning the success of fire safety strategies for tall buildings.

\section{Acknowledgements}

This work formed part of the EPSRC funded Real Fires for the Safe Design of Tall Buildings project (Grant No. EP/J001937/1) at the University of Edinburgh. The authors are extremely grateful to EPSRC for funding this work. The authors would like to thank the Bombeiros Voluntários da Malveira for provision of the experimental building and support during the test. The authors are once again indebted to Rockwool International A/S for providing a significant amount of materials used in this experiment. The authors would like to thank Levantina de Pesaje for their support designing the mass loss system.

\section{References}

1. A. Cowlard, A. Bittern, C. Abecassis-Empis, and J.L. Torero, J. L. (2013). Some considerations for the fire safe design of tall buildings. International Journal of High-Rise Buildings, 2(1), 15.

2. CTBUH. The Skyscraper Centre, The Global Tall Building Database of the CTBUH. http://www.skyscrapercenter.com/ (accessed 28/11/2018).

3. A.H. Majdalani, J.E. Cadena, A. Cowlard, F. Munoz, F., and J.L. Torero (2016). Experimental characterisation of two fully-developed enclosure fire regimes. Fire Safety Journal, 79, 10-19. https://doi.org/10.1016/j.firesaf.2015.11.001.

4. J.L. Torero, A.H. Majdalani, C. Abecassis-Empis, and A. Cowlard (2014). Revisiting the compartment fire. Fire Safety Science, 11, 28-45. https://doi.org/2010.3801/IAFSS.FSS.11-28.

5. S.H. Ingberg (1928). Test of the Severity of Building Fires. U.S. Bureau of Standards.

6. D. Evans, D. Gross, and R. Wright (1997). Test of the Severity of Building Fires. Retrieved from https://nvlpubs.nist.gov/nistpubs/sp958-lide/028-032.pdf.

7. K. Fujita, Characteristics of a Fire inside a Non-Combustible Room and Prevention of Fire Damage - Report No. 2(h), Japanese Building Research Institute, Japan.

8. K. Kawagoe (1958). Fire Behaviour in Rooms. Report of BRI No.27, Japanese Building Research Institute.

9. K. Kawagoe and T. Sekine (1963). Estimation of Fire Temperature-Time Curve in Rooms. Occasional Report No. 11, Japanese Building Research Institute, Japan.

10. D. Drysdale (2011). The Post-flashover Compartment Fire in Introduction to Fire Dynamics, $3^{\text {rd }}$ Edition, John Wiley \& Sons, West Sussex.

11. P.H. Thomas and A.J.M. Heselden (1972). Fully-developed Fires in Single Compartments: A Co-operative Research Programme of the Conseil International Du Bâtiment. Building Research Establishment, Fire Research Station. 
12. T.Z. Harmathy (1972) A new look at compartment fires, part I. Fire Technology, 8(3), 196217. https://doi.org/10.1007/BF02590544.

13. BS EN 1991-1-2 (2002) Eurocode 1: Actions on structures. Part 1-2: General actions - actions on structures exposed to fire. BSI.

14. J.L. Torero, A. Law, and C. Maluk (2015). Defining the thermal boundary condition for protective structures in fire. Engineering Structures, 149, 104-112, https://doi.org/10.1016/j.engstruct.2016.11.015.

15. A. Usmani, Y.C. Chung, and J.L. Torero (2003). How did the WTC towers collapse: a new theory. Fire Safety Journal, vol. 38(6), 501-533. https://doi.org/10.1016/S03797112(03)00069-9.

16. J. Stern-Gottfried, G. Rein, L.A. Bisby, and J.L. Torero (2010). Experimental review of the homogenous temperature assumption in post-flashover comparment fires. Fire Safety Journal, 45(4), 249-261. https://doi.org/10.1016/j.firesaf.2010.03.007.

17. G. Rein, X. Zhang, J.L. Torero, P. Williams, B. Hume, A. Heise, A. Jowsey, A., and B. Lane, B (2007). Multi-storey fire analysis for high-rise buildings. $11^{\text {th }}$ Interflam, 605-616, London, September 2007.

18. J. Stern-Gottfried and G. Rein (2012). Travelling fires for structural design-Part I: Literature review. Fire Safety Journal, 54, 74-85. https://doi.org/10.1016/j.firesaf.2012.06.003.

19. J. Stern-Gottfried and G. Rein (2012). Travelling fires for structural design-Part II: Design methodology, Fire Safety Journal, 54, 96-112. https://doi.org/10.1016/j.firesaf.2012.06.011.

20. E. Rackauskaite, C. Hamel, A. Law and G. Rein (2015). Improved Formulation of Travelling Fires and Application to Concrete and Steel Structures. Structures, 3, 250-260. https://doi.org/10.1016/j.istruc.2015.06.001.

21. X. Dai, S. Welch, and A. Usmani (2017). A critical review of "travelling fire" scenarios for performance-based structural engineering. Fire Safety Journal, 91, 568-578. https://doi.org/10.1016/j.firesaf.2017.04.001.

22. J.P. Hidalgo et al. (2017) An experimental study of full-scale open floor plan enclosure fires. Fire Safety Journal, 89, 22-40. https://doi.org/10.1016/j.firesaf.2017.02.002.

23. C. Maluk, B. Linnan, A. Wong, J.P. Hidalgo, J.L. Torero, A.C. Abecassis-Empis and A. Cowlard (2017). Energy distribution analysis in full-scale open floor plan enclosure fires. Fire Safety Journal, 91, 422-431. https://doi.org/10.1016/j.firesaf.2017.04.004.

24. J.P. Hidalgo et al. (2017) A Thin Skin Calorimeter (TSC) for quantifying irradiation during large-scale fire testing. International Journal of Thermal Sciences, 112, 383-394. https://doi.org/10.1016/j.ijthermalsci.2016.10.013.

25. B.J. McCaffrey and G. Heskestad (1976). A robust bidirectional low-velocity probe for flame and fire application. Combustion and Flame, 26, 125-127. https://doi.org/10.1016/00102180(76)90062-6.

26. V. Gupta, C. Maluk, J.L. Torero, and J.P. Hidalgo. Analysis of the Flow Fields through an Opening in a Large-Scale Compartment Fire Experiment. (Accepted for oral presentation in the $9^{\text {th }}$ International Seminar on Fire and Explosion Hazards 2019).

27. CIBSE Guide E: Fire Safety Engineering (2010). CIBSE. ISBN 9781906846138.

28. PCR Collier (2007). Fire Properties of Floor Coverings: New Fire Tests Methods and Acceptable Solutions. BRANZ Study Report 181. BRANZ Ltd, Judgeford, New Zealand. 
https://www.branz.co.nz/cms show download.php?id=0d2ebab737a645d7f1f5608789b3e

$2 \quad \underline{\mathrm{d} 16705815 \mathrm{~d} 4}$ (accessed 28/11/2018).

29. B. Moghtaderi and D.F. Fletcher (1988). Flaming Combustion Characteristics Of WoodBased Materials. AOSFT 3, 209-219. http://www.iafss.org/publications/aofst/3/209/view

30. M.J. Hurley, D.T. Gottuk, J.R. Hall Jr., K. Harada, E.D. Kuligowski, M. Puchovsky, J.L. Torero, J.M. Watts Jr., and C.J. Wieczorek (2016). SFPE Handbook of Fire Protection Engineering, $5^{\text {th }}$ edition, Springer-Verlag New York. https://doi.org/10.1007/978-1-49392565-0.

31. J.P. Hidalgo, S. Welch, and J.L. Torero (2015). Performance criteria for the fire safe use of thermal insulation in buildings. Construction and Building Materials, vol. 100, pp. 285-297. https://doi.org/10.1016/j.conbuildmat.2015.10.014.

32. D. Drysdale (1986). Fundamentals of the Fire Behaviour of Cellular Polymers. In: Fire and Cellular Polymers. Springer, Dordrecht. https://doi.org/10.1007/978-94-009-3443-6 4.

33. T. Goode (2018). Characterisation of the Malveira Fire Test. Master of Engineering Thesis, The University of Queensland.

34. W.S. Cleveland and S.J. Devlin (1988). Locally weighted regression: an approach to regression analysis by local fitting. Journal of the American Statistical Association, vol. 83, pp. 596-610. https://doi.org/10.1080/01621459.1988.10478639.

35. J.G. Quintiere (2006). Fundamentals of fire phenomena. John Wiley \& Sons, Inc.. 